EDNALDO COELHO PEREIRA

\title{
INFRAESTRUTURA TECNOLÓGICA EM CURSOS NA MODALIDADE PRESENCIAL MEDIADO POR TECNOLOGIA PARA O ESTADO DO AMAZONAS
}


EDNALDO COELHO PEREIRA

\title{
INFRAESTRUTURA TECNOLÓGICA EM CURSOS NA MODALIDADE PRESENCIAL MEDIADO POR TECNOLOGIA PARA O ESTADO DO AMAZONAS
}

\author{
Dissertação de mestrado em \\ engenharia elétrica apresentada à \\ Escola Politécnica da Universidadede \\ São Paulo
}


EDNALDO COELHO PEREIRA

\title{
INFRAESTRUTURA TECNOLÓGICA EM CURSOS NA MODALIDADE PRESENCIAL MEDIADO POR TECNOLOGIA PARA O ESTADO DO AMAZONAS
}

\author{
Dissertação de mestrado em \\ engenharia elétrica apresentada à \\ Escola Politécnica da Universidadede \\ São Paulo \\ Área de Concentração: \\ Sistemas Digitais
}

Orientador:

Prof. Dr. Edison Spina

São Paulo

2010 


\section{FICHA CATALOGRÁFICA}

Pereira, Ednaldo Coelho

Infraestrutura tecnológica em cursos na modalidade presencial mediado por tecnologia para o Estado do Amazonas / E.C. Pereira. -- São Paulo, 2010.

$64 \mathrm{p}$.

Dissertação (Mestrado) - Escola Politécnica da Universidade de São Paulo. Departamento de Engenharia de Computação e Sistemas Digitais.

1.Educação à distância 2.Aprendizagem tecnológica 3.InteGração de tecnologias I.Universidade de São Paulo. Escola Politécnica. Departamento de Engenharia de Computação e Sistemas Digitais II.t. 


\section{DEDICATÓRIA}

Dedico este trabalho a minha filha Maria Clara. 


\section{AGRADECIMENTOS}

A Deus por ter permitido sobreviver ao acidente ocorrido no início do MINTER.

Ao Prof. Dr. Edison Spina que me orientou na confecção deste trabalho.

A direção da Escola Superior de Tecnologia - EST, por ter proporcionado condições favoráveis ao cumprimento das atividades relativas ao MINTER.

A equipe de coordenação do TADS pela compreensão dispensada durante os meus afastamentos no decorrer do MINTER. 


\section{RESUMO}

O presente trabalho faz uma investigação através de experimentos práticos a respeito da infra-estrutura tecnológica de ferramentas computacionais que auxiliem o processo ensino aprendizagem e equipamentos utilizados na transmissão de aulas do Sistema de educação implantado no Estado do Amazonas denominado "Presencial Mediado por Recursos Tecnológicos", tendo como cenário para experimentos o curso superior de Tecnologia em Análise e Desenvolvimento de Sistemas - TADS da Universidade do Estado do amazonas - UEA.

Palavras chaves: Educação à distância, Aprendizagem tecnológica, Integração de tecnologias. 


\begin{abstract}
The present study is a research through practical experiments regarding the technological infrastructure of computational tools that assist the teaching and learning equipment used in transmitting lessons of education system introduced in the State of Amazonas called "Face Mediated by Technology Resources" , taking as case study the college of Technology in Analysis and Systems Development - TADS State University of Amazonas-UES.
\end{abstract}

Keywords: Distance education, learning technology, integration of technologies. 


\section{LISTA DE ILUSTRAÇÕES}

Figura 1: Modelo tecnológico utilizado no EPMRT. ................................ 22

Figura 2: Processos inter-relacionados para construção do conhecimento. 24

Figura 3: Visão dos componentes do curso TADS ................................ 28

Figura 4: Disposição dos alunos em sala de aula .................................... 38

Figura 5: Disposição dos alunos em sala de aula com uso do computador 39 


\section{LISTA DE TABELAS}

Tabela 1: Combinação entre os novos paradigmas e as TICs................... 12

Tabela 2: Características de Ambientes Virtuais de Aprendizagem ............. 17

Tabela 3: Cursos e alunos beneficiados pelo EPMRT ............................. 20

Tabela 4: Municípios integrantes do curso TADS .................................... 26

Tabela 5: Resultados obtidos na avaliação do AVA ............................... 33

Tabela 6: Comparação entre os modelos de ensino................................ 45 


\section{LISTA DE ABREVIATURAS}

EAD - Educação a Distância

PROFORMAR - Programa de Formação e Valorização dos Profissionais de Educação

SPMRT - Sistema Presencial Mediado por Tecnologia

PMRT - Presencial Mediado por Tecnologia

EPMRT - Ensino Presencial Mediado por Recursos Tecnológicos

AVA - Ambiente Virtual de Aprendizagem

QoS - Quality of Service

UEA - Universidade do Estado do Amazonas

SEDUC / AM - Secretaria de Educação do Estado do Amazonas

TCC - Trabalho de Conclusão de Curso

IES - Instituição de Ensino Superior

MEC - Ministério da Educação

CSCW - Computer-Supported Cooperative Work - Computação Cooperativa

CMC - Computação Mediada por Computador

SGA - Sistema de Gestão de Aprendizagem

TIC - Tecnologia da Informação e Comunicação 


\section{SUMÁRIO}

LISTA DE ILUSTRAÇÕES ................................................................... IV

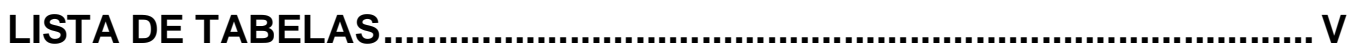

LISTA DE ABREVIATURAS ............................................................... VI

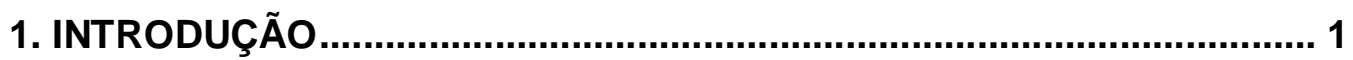

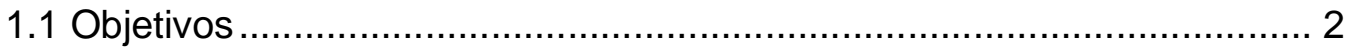

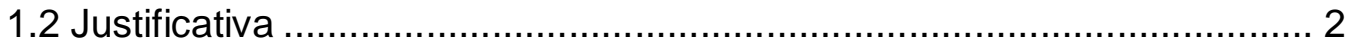

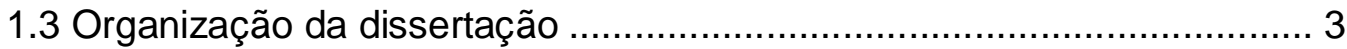

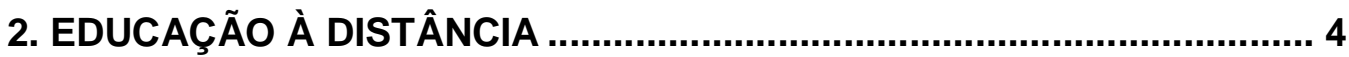

2.1 Educação superior a distância no Brasil .............................................. 4

2.2 Legislação sobre EaD no Brasil ......................................................... 6

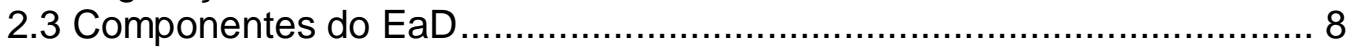

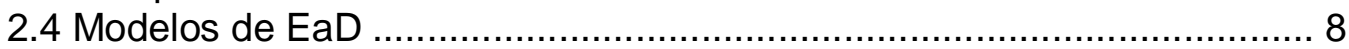

2.4.1 Aprendizagem por e-learning .................................................... 9

2.4.2 Aprendizagem por m-learning .................................................... 10

2.4.3 Aprendizagem e o papel das TICs ................................................... 11

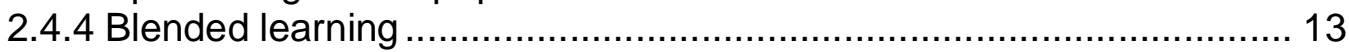

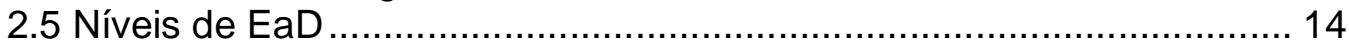

2.6 Ferramentas computacionais utilizadas na EaD ................................ 15

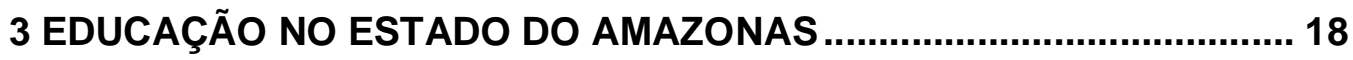

3.1 A Universidade do Estado do Amazonas - UEA ................................... 19

3.1.2 Secretaria de Educação do Estado do Amazonas (SEDUC-AM) ........ 21

3.2 Ensino Presencial Mediado por Recursos Tecnológicos - EPMRT ......... 21

4 A CONSTRUÇÃO DO CONHECIMENTO ATRAVÉS DO EPMRT ........... 24

4.1 Curso de Tecnologia em Análise e Desenvolvimento de Sistemas -

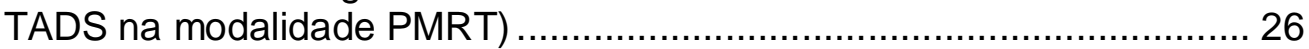

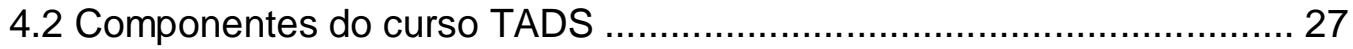

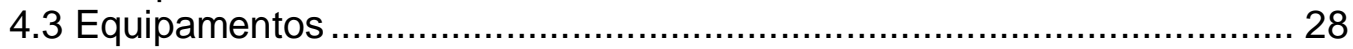

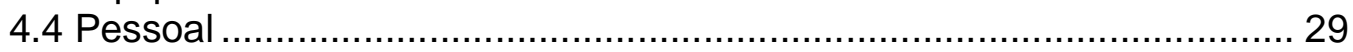

4.5 Experimentos de Ferramentas computacionais de suporte .................... 29

4.5.1 AVA como ferramenta auxiliar no EPMRT ...................................... 30

4.5.2 Metodologia de avaliação do AVA ……………………………..... 32

4.5.3 A Importância do AVA no EPMRT …………………………........ 35

4.6 Experimentos de Infra-estrutura mínima de equipamentos em sala de

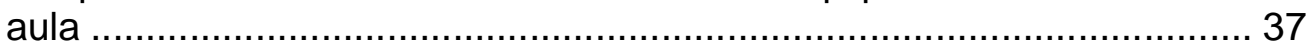

4.6.1 Fatores relevantes observados durante o experimento ...................... 39

5 COMPARAÇÃO ENTRE OS MODELOS DE ENSINO.............................. 41

5.1 Questões relacionadas a professores.................................................. 41

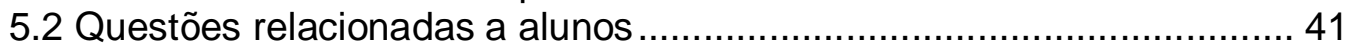


5.3 Questões relacionadas às disciplinas ................................................. 42

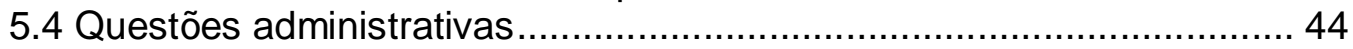

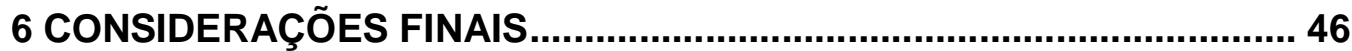

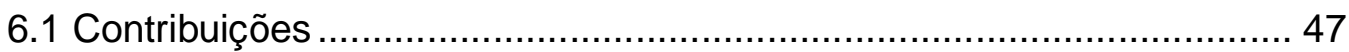

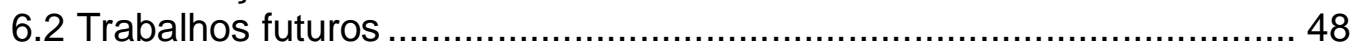

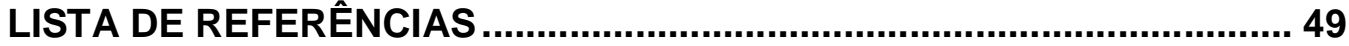




\section{INTRODUÇÃO}

Devido ao crescimento da modalidade de ensino a distância, as instituições de ensino vêm se adaptando e investindo em diversas tecnologias que auxiliam nesse processo de aprendizagem, e procuram contratar professores que estejam compromissados a encarar esse novo desafio.

A característica principal do $\mathrm{EaD}$ é que o ensino se faz sem a presença física do professor ou do aluno ao mesmo tempo em um mesmo local geográfico, através de algum meio tecnológico como, por exemplo, a televisão, podendo os dois estarem separados espacialmente e/ou temporariamente (MORAN).

Novas ferramentas, principalmente no campo da informática, estão sendo desenvolvidas nessa modalidade de ensino com o intuito de elevar o padrão de qualidade da educação brasileira.

A Universidade do Estado do Amazonas, no ano de 2002, através do Programa de Formação e Valorização dos Profissionais de Educação (PROFORMAR) criou o que hoje é chamado de Ensino Presencial Mediado por Recursos Tecnológicos (EPMRT).

No EPMRT a transmissão das aulas é feita ao vivo, via satélite, através de televisores, para salas de aula remotas, onde em cada sala há um professor auxiliar denominado assistente, o que de certa forma, o diferencia da EaD propriamente dita, uma vez que o ensino não se torna unidirecional, já que este professor assistente também elabora, aplica e corrige atividades didáticas para os alunos. Assim este trabalho está focado na análise e melhoria da infra-estrutura tecnológica utilizada pelos cursos na modalidade presencial mediada por recursos tecnológicos, tendo como cenário para experimentos o curso de Tecnologia em Análise e Desenvolvimento de Sistema. 


\subsection{Objetivos}

O presente trabalho tem por objetivo propor melhorias na infra-estrutura tecnológica educacional utilizada na modalidade de Ensino Presencial Mediado por Recursos Tecnológicos da Universidade do Estado do Amazonas, através da implantação de ferramentas computacionais que auxiliem no processo ensino-aprendizagem e propor mudanças na plataforma tecnológica utilizada em sala de aula tendo como cenário para experimentos o curso de Tecnologia em Análise e Desenvolvimento de Sistemas nessa modalidade.

\subsection{Justificativa}

Nos últimos anos o avanço da tecnologia da informática mudou os conceitos de ensino e de trabalho, no Amazonas a dificuldade de locomoção na região por falta de rodovias e a grande extensão territorial, a baixa densidade demográfica e o subdesenvolvimento secular imposto à população ribeirinha, torna a tarefa de levar educação de qualidade uma missão árdua.

A UEA que nasceu como uma universidade moderna incorporando tecnologias educacionais de ponta, utilizando-se particularmente da informática, pela massificação do uso de microcomputadores combinados com uma rede de acesso a internet, não poderia ficar alheia a esse processo e criou no ano de 2001 uma modalidade de ensino denominada "Ensino Presencial Mediado por Recursos Tecnológicos" e desde então já foram beneficiados por essa iniciativa 20.841 alunos, (BARBOSA; RAMOS, 2008). Mesmo com um número tão expressivo de alunos já beneficiados pelo modelo, ainda não foi realizado um estudo capaz de propor melhorias na qualidade da infra-estrutura, definindo critérios para os serviços de transmissão de aula, equipamentos mínimos necessários para oferecer uma aula de qualidade e softwares que possam servir de meio auxiliar no processo ensino aprendizagem. 


\subsection{Organização da dissertação}

Este trabalho foi dividido em seis capítulos, onde o primeiro delimita o tema, especifica o objetivo e traz à justificativa, o restante do texto está assim dividido:

- O capítulo 2 traz definições e conceitos utilizados neste trabalho a respeito de Educação a Distância.

- O capítulo 3 mostra a maneira como a educação pública é feita no Estado do Amazonas dando ênfase para o trabalho feito pela Secretaria de Educação do Estado e a Universidade estadual que utilizam o modelo de Educação Presencial Mediado por Recursos Tecnológicos - EPMRT.

- O capítulo 4 descreve os experimentos realizados tendo como cenário o curso de Tecnologia em Análise e Desenvolvimento de Sistemas oferecido através do EPMRT.

- O capítulo 5 mostra uma comparação feita entre os modelos de educação: EPMRT x EP x EaD.

- O capítulo 6 traz as considerações finais, contribuições, sugestões para trabalhos futuros e a lista de referências utilizadas. 


\section{EDUCAÇÃO À DISTÂNCIA}

O termo Educação a distância abrange as diversas formas de estudo, em todos os níveis, que não dispõem da supervisão contínua e imediata de tutores ou professores presentes com seus alunos em salas de aula ou nos mesmos locais, mas que ainda se beneficiam do planejamento, orientação e ensino oferecidos por uma organização tutorial ( BELLONI, 2003).

Diversos autores conceituam a EaD conforme sua própria visão ou entendimento, porém, todos concordam que para ela existir de fato, o parâmetro primordial é a separação no tempo e/ou espaço entre o professor e o aluno.

Ao conceito de $\mathrm{EaD}$, é incorporada também a utilização de tecnologias, principalmente as telemáticas (internet, CD-ROM, telefone, etc..), como forma de transmissão de conhecimento entre o professor e o aluno. Ou seja, o processo de ensino-aprendizagem é realizado através de multimídias (textos, fotos, sons e imagens computadorizados), o que caracteriza a adaptação à acelerada evolução tecnológica, visto que a história do surgimento da EaD conta que essa transmissão era realizada apenas pela troca de correspondências.

Devido a esse rápido desenvolvimento, as tecnologias de informação e comunicação, tem sido um forte agente de aprendizagem que conduz a uma vasta combinação de recursos tecnológicos e humanos (MEHLECKE, 2003). Como a EaD decorre da necessidade de se proporcionar o estudo a pessoas impossibilitadas de deslocarem-se para uma sala de aula presencial, vê-se como uma excelente forma de apoio a este tipo de ensino a introdução de ferramentas tecnológicas que proporcionem o uso de novas metodologias com o intuito de melhorar o padrão de qualidade da educação.

\subsection{Educação superior a distância no Brasil}

Podemos considerar o momento atual como um período de transição da revolução tecnologia iniciada na década de 1970 até a entrada no século 
XXI, com maior clareza sobre não somente a necessidade de mudanças, mas também quanto a seu direcionamento. Segundo Castells (2003, p.69): O que caracteriza a atual revolução tecnológica não é a centralidade de conhecimentos e informação, mas a aplicação desses conhecimentos e dessa informação para a geração de conhecimentos e de dispositivos de processamento/comunicação da informação, em um ciclo de realimentação cumulativo entre a inovação e o uso.

Embora, no Brasil a entrada da EaD na educação superior seja bastante recente, essa modalidade já vem sendo adotada, há bem mais tempo por outros países. A Universidade de Londres pode ser apontada como um marco histórico. Fundada em 1836, teve papel pioneiro na extensão da educação universitária para todos. Independente de raça, credo, gênero ou país de origem. Em 1878, tornou-se a primeira universidade na GrãBretanha a admitir mulheres. Em 1858, com a concessão dada pela rainha Vitória, teve o seu sistema externo estabelecido, abrindo o processo de EaD para todos aqueles que não podiam ir a Londres estudar. Constituiu-se na primeira universidade a oferecer diplomas a estudantes pelo mundo, sendo que llhas Maurício se tornou o primeiro país a sediar seus exames, em 1865. A EaD entra no Brasil no início do século XX, a partir da oferta de cursos profissionalizantes, de nível introdutório e sem exigência de escolarização prévia. Ofertados por instituições privadas, por base material impresso distribuído por correspondência. Esse modelo consolida-se na década de 1940, com a criação do Instituto Monitor (1939) e do Instituto Universal Brasileiro (1941). Pode-se considerar essa como a primeira geração de EaD. Posteriormente com o rádio e a televisão, foi utilizada para promover programas de alfabetização, ligados principalmente a Igreja Católica, e de ensino supletivo para complementação da Educação de Jovens e Adultos EJA. 


\subsection{Legislação sobre EaD no Brasil}

A lei que impulsionou as atividades de EaD no Brasil foi a Lei 9.394, de 20 de dezembro de 1996 - Lei de Diretrizes e Bases da Educação, Artigo 80 estabelecendo que: "O Poder Público incentivará o desenvolvimento e a veiculação de programas de ensino a distância, em todos os níveis e modalidades de ensino, e de educação continuada". Diante disto, as instituições de ensino sentiram-se mais seguras e amparadas para continuar ou entrar no negócio da educação à distância.

Anos depois, com o objetivo de incentivar e possibilitar que as instituições de ensino superior (IES) entrassem na era da educação a distância, o Ministério da Educação (MEC) lançou a Portaria MEC no 2.253, em 18 de outubro de 2001, onde no Art 1ำ determinava que: "As instituições de ensino superior do sistema federal de ensino poderão introduzir, na organização pedagógica e curricular de seus cursos superiores reconhecidos, a oferta de disciplinas que, em seu todo ou em parte, utilizem método não presencial". Entretanto, o MEC impôs a limitação de que as IES só poderiam ofertar $20 \%$ das disciplinas a distância, como consta no Art $1^{\circ}$, o $\S 1^{\circ}$ desta mesma portaria.

No ano de 2005, o Decreto $\mathrm{n}^{\circ}$ 5622, de 19 de dezembro de 2005, regulamentou o Art. 80 da Lei n 9.394, de 20 de dezembro de 1996, que estabelece as diretrizes e bases da educação nacional. O Art. 1ำ do referido decreto, caracteriza a EaD como "modalidade educacional na qual a mediação didático-pedagógica nos processos de ensino e aprendizagem ocorre com a utilização de meios e tecnologias de informação e comunicação, com estudantes e professores desenvolvendo atividades educativas em lugares ou tempos diversos". Esse decreto estabelece a organização geral da EaD, os níveis e modalidades educacionais que poderão ser ofertados pelas IES e todas as exigências para se obter o credenciamento das instituições para oferta de cursos e programas na modalidade a distância. Esse Decreto estabelece ainda, que os cursos superiores ministrados a distância não poderão ter a duração mínima inferior 
à definida na modalidade presencial e terão equivalências e aproveitamentos garantidos.

Com a preocupação de se manter certo padrão de qualidade nos programas de EaD, o MEC divulgou Indicadores de Qualidade para essa modalidade de ensino, que têm como objetivo orientar as IES a conseguir maior qualidade em seus produtos e processos, sendo eles:

- Integração com políticas, diretrizes e padrões de qualidade definidos para o ensino como um todo e para o curso específico;

- Desenho do projeto: a identidade da EaD;

- Equipe profissional multidisciplinar;

- Comunicação/interatividade entre professor e aluno (tutoria);

-Qualidade dos recursos educacionais;

- Infra-estrutura de apoio;

- Avaliação de qualidade contínua e abrangente;

- Convênios e parcerias;

- Edital e informações sobre o curso à distância;

- Custos de implementação e manutenção.

O governo federal, com o objetivo de incentivar a expansão da EaD, aprovou a Lei no 11.273, de 06 de fevereiro de 2006, que cria bolsas de estudo e de pesquisa para professores comprometidos com a educação à distância, tutores e participantes de cursos ou programas de formação inicial. Através desta lei, é garantida uma bolsa de até $R \$ 1.200,00$, além do salário, para professores envolvidos em projetos de EaD.

A legislação mais recente sobre EaD é a Portaria Normativa 02/MEC, de 10 de janeiro de 2007, que dispõe a respeito dos procedimentos de regulação e avaliação da educação superior na modalidade à distância. Esta legislação define que somente IES credenciadas podem ofertar cursos superiores à distância e reafirma a necessidade de pólos estruturados para atender as atividades presenciais obrigatórias. Esses recentes documentos legais são fundamentais para a orientação das IES que querem se inserir no contexto da EaD. 


\subsection{Componentes do EaD}

A utilização de ferramentas tecnológicas serve de auxílio tanto a professores como a alunos no processo ensino-aprendizagem a distância, promovendo, através do uso da internet, novas possibilidades de ensino não presencial. Quatro elementos são citados por Landins (1997) como necessários para o sistema de EaD, porém já se pode considerar cinco, sendo elas:

- O aluno: o personagem principal do processo educativo.

- O docente: o personagem atuante que irá motivar e possibilitar a aprendizagem no ambiente virtual.

- A comunicação: que poderá ser realizada através de material impresso, audiovisual, telemática e a tutoria mediando o presencial e o virtual.

- A estrutura e organização: de materiais, distribuição de materiais, processos de comunicação e avaliação.

- O tutor: a pessoa que vai manter contato físico com os alunos a fim de proporcionar auxílio ao docente e ao ensino.

O eventual acesso aos meios computacionais pela população brasileira, juntamente com o incentivo e a fiscalização pelo MEC, caracterizam-se como fatores determinantes para a melhoria contínua dos programas de EaD (ATAIDE, 2008).

\subsection{Modelos de EaD}

Nas últimas três décadas o aumento da comunicação humana mediada pelo computador para fins educativos levou a uma proliferação de tecnologias com o propósito de oferecer ambientes educacionais on-line. Desde o e-mail até os chats e as plataformas de aprendizagens educacionais, a comunicação humana mediada pelo computador tem sido uma ferramenta de uso crescente no ensino superior, serão apresentados a seguir alguns tipos de aprendizagem com mediação tecnológica. 


\subsubsection{Aprendizagem por e-learning}

Várias características foram assinaladas para salas de aula colaborativas on-line. Warschauer (1997) e Harasim et al. (2005) afirmam que salas de aula on-line tem um imenso potencial para modelos pedagógicos colaborativos, demonstrados por três características:

Comunicação de grupo a grupo ( e não só de um a um ), permitindo que cada participante se comunique diretamente com outros colegas da sala de aula on-line.

Independência de lugar e tempo, permitindo que estudantes acessem a sala de aula on-line de qualquer localidade com acesso a internet, a qualquer hora do dia, dando-lhes assim o tempo necessário para desenvolver uma reflexão crítica e uma análise dos temas postados na discussão.

Interação via comunicação mediada por computador que requer que os estudantes organizem suas idéias e pensamentos através da palavra escrita e compartilhem esses pensamentos e comentários em um formato que os outros colegas possam facilmente ler, digerir e tecer comentários e exercitar tarefas intelectuais.

Essas características induzem a mudança de um ensino do tipo tradicional, centrado no professor e suas palestras, para outro modelo colaborativo, no qual os estudantes contribuem com a maior parte das mensagens.

Teles e Duxbury (2000) descobriram que os professores contribuem com menos mensagens que os estudantes. No caso da sala de aula presencial, os professores dominavam de sessenta a oitenta por cento das aulas, muitas vezes com palestras expositivas. Já no caso das disciplinas on-line essa porcentagem do professor foi somente de dez a vinte por cento do total das mensagens postadas on-line. Ou seja, a participação on-line é inversa a participação presencial em termos de porcentagem estudantil e docente no tempo e geração no conteúdo das aulas.

Essa mudança na contribuição de professores e alunos na sala de aula virtual (Garland, Wang e Teles, 1999) aponta para os indícios de um novo papel do professor no processo de ensino-aprendizagem, quando este se dá on-line. 


\subsubsection{Aprendizagem por m-learning}

Em junho de 1999, ministros da educação de 29 países que então compunham a Comunidade Européia, firmaram a Declaração de Bolonha. Esse documento estabeleceu dois conceitos que nortearam as ações da Comunidade Européia, no sentido de facilitar a integração nos aspectos educacionais. O primeiro conceito foi a necessidade de estabelecer critérios e parâmetros para que os sistemas educacionais dos países da Comunidade permitissem a mobilidade dos cidadãos afim de facilitar o reconhecimento de seus diplomas em todo território europeu. $O$ segundo conceito permitia o deslocamento de estudantes para aprendizagem e treinamento, e também de professores e burocratas. Foram esses dois parâmetros que deram origem ao conceito de mobile learning (m-learning) - literalmente, aprendizagem móvel, ou aprendizagem em movimento.

Antes do desenvolvimento desse conceito, dois outros conceitos tornam-se paradigmas nos programas de educação dos ministérios euroupeus: Lifelong Learning e mon-formal Learning (aprendizagem não formal). O primeiro (Working , Group 2) (aprendizagem por toda vida) diz respeito a todas as atividades formais ou não formais que aumentam o conhecimento e as habilidades do indivíduo ao longo de sua vida. Não é uma definição acadêmica e não está suficientemente inserido no universo da educação. $O$ segundo abrange todo conhecimento adquirido por meio de atividades formais e informais tanto no local de trabalho quanto na vida em sociedade. Non-formal Learning, também é conhecido como Informal Learning, apesar de vários departamentos de universidades discutirem se os dois conceitos representam ou não a mesma coisa. Os adeptos do Informal learning argumentam que este conceito opera apenas no nível individual, enquanto 0 non-formal pode ser entendido como um conceito operante coletivo. Ambas as experiências se antepõem ao ensino formal, que são, em resumo, todas as atividades educacionais planejadas e estruturadas tanto no sistema escolar quanto no local de trabalho. 
Decorre daí que Lifelong learning torna-se uma necessidade para as sociedades que percebem na informação e na comunicação valores concretos e patrimônio (imaterial). A aferição dessa aprendizagem aumenta a velocidade de desenvolvimento naquilo que se convenciona chamar de Era do Conhecimento, também utilizamos o conceito de 'Idade Mídia'. Nesses tempos, conhecimentos decorrentes de informação e comunicação quando utilizado produtivamente pelo individuo, soma-se ao capital social de uma comunidade. Lifelong Learning requer do cidadão uma compreensão que abriga tanto o processo individual de amadurecimento pessoal quanto as necessidades interpessoais e coletivas da sua comunidade. Pressupõe, portanto, uma constante adaptação.

\subsubsection{Aprendizagem e o papel das TICs}

A internet obteve sucesso mundial por contar com uma adequada plataforma facilitadora representada pelas Tecnologias de informação e comunicações TICs. A sua utilização cada vez mais intensa pelas ciências cognitivas plasmou um novo campo de conhecimento denominado knowlegde media (Eisenstadt, 1995, citado in Mega-universities, Daniel, 1996) ou mídia do conhecimento, também impregnado de termos técnicos em inglês. A importância do 'aprender fazendo', graças as TICs e a capacidade crescente de inovar, faz com que a dinâmica cognitiva da sociedade se tenha tornado em questão crucial. Por meio das TICs, os modelos de aprendizagem finamente ultrapassam o universo limitado dos educadores e invadem todas as células da vida social e econômica. Tal qual a frase atribuída tanto a Lloyd quanto a George Clenenceau: "A guerra é algo sério demais para deixar apenas nas mãos dos generais. Pode-se hoje afirmar que a educação é um assunto complexo demais para deixar apenas com os educadores".

A nova dimensão da educação, que melhor se expressa pelo termo 'aprendizagem' - mais abrange - atinge todas as organizações, seja de caráter acadêmico ou mesmo comercial. Os novos modelos de aprendizagem utilizam intensamente as TICs e coincidem com a inovação 
em todos os níveis da vida humana. A 'inovação' em EaD passa sempre pelo uso crescente das TICs, comprovando uma relação biunívoca entre conhecimento e mídia. Onde estiver um, estará o outro, uma vez que, simultaneamente, se tornam indispensáveis às práticas concretas de aprendizagem.

A combinação constante entre os novos paradigmas da aprendizagem e as TICs pode ser visualizada pela tabela 1.

O papel exercido pelas TICs e a valorização cada vez maior da inovação extrapolam em muito $o$ que se vem observando no processo de aprendizagem e no uso progressivo da EaD, denominada no novo paradigma de aprendizagem flexível. A multipresença da inovação, ou sua ubiquidade, já permite antever nesse limiar do século XXI, em sequência ou consequência das sociedades da aprendizagem e da informação e do conhecimento, o pleno processo de gestação tecnológica de uma nova sociedade, que poderia vir a ser denominada, em curto espaço de tempo, 'sociedade da inovação'.

Tabela 1: Combinação entre os novos paradigmas e as TICs.

\begin{tabular}{|l|l|}
\hline \multicolumn{2}{|c|}{ Da educação a aprendizagem } \\
\hline Antigo paradigma & Novo paradigma \\
\hline Instalações fisicas (prédios escolares) & Ciberespaço \\
\hline Frequência obrigatória e horário rigido & Conveniência de local e horário \\
\hline Ensinar & Aprender a aprender \\
\hline Curriculo minimo, disciplinas obrigatórias e pré-requisitos & Conteúdos significativos e flexíveis \\
\hline Unidisciplinaridade & Inter, multi e transdisciplinaridade \\
\hline Pedagogia & Andragogia \\
\hline Transmissão do conhecimento & Aprendizagem coletiva \\
\hline Educação formal & Educação não formal \\
\hline Formação com duração préfixada & Formação ao longo da vida \\
\hline Educação a distância & Aprendizagem aberta e flexivel \\
\hline Economia de bens e serviços & Economia do conhecimento \\
\hline Professor & Orientador de aprendizagem \\
\hline Avaliação quantitativa & Avaliação qualitativa \\
\hline Diplima/certificado & Satisfação de aprender \\
\hline
\end{tabular}

Fonte: (Litto, Formiga: 2009) 


\subsubsection{Blended learning}

A incorporação das Tecnologias da Informação e Comunicação - TICs à EaD tornou essa modalidade educacional mais complexa devido as características da tecnologia digital de flexibilizar as relações entre espaço e tempo, propiciar a interação entre as pessoas e destas com as informações disponibilizadas e com as tecnologias em uso, ampliar 0 acesso a informações hipermidiáticas continuamente atualizadas, empregar mecanismos de busca e seleção de informações, permitir o registro de pessoas e produtos, a recuperação, articulação e reformulação da informação, favorecer a mediação pedagógica em processos síncronos ou assíncronos, criar espaço para a representação do pensamento e a produção do conhecimento. A interatividade inerente às TICs potencializa a criatividade, a expressão do pensamento e a colaboração, mas a tecnologia em si mesma, qualquer que seja ela, não é suficiente para garantir a qualidade da EaD, nem indica a abordagem educacional. Assim convive-se com a tensão entre a mudança impulsionada pelas possibilidades da tecnologia e a estabilidade encapsuladora das práticas pedagógicas pautadas pela transmissão massiva de informações. Atentos as tensões observadas e as evidencias da necessidade de mudanças, pesquisadores buscam resgatar metodologias flexíveis e orientadas para o diálogo e a democracia (Belloni, 1979), na perspectiva do estar junto virtual (Valente, 2002), tendo a experiência como fonte da aprendizagem (Dewey, 1979) aberta (Khvilon, 2002), que se desenvolve em qualquer tempo conforme demandas e necessidades dos aprendizes.

Atualmente muitos estudos sobre EaD, educação presencial ou híbrida em ambientes virtuais, enfatizam as características e funcionalidades das tecnologias. No entanto, é preciso entender sobre como se pretende e considerar as analogias e as diferenças entre a aprendizagem de adultos e de crianças e de grupos com necessidades especificas. Torna-se, assim, necessário avançar para além das potencialidades tecnológicas e relações pedagógicas entre professor e alunos baseadas em abordagens instrucionista ou construtivista, a fim de aprofundar a compreensão sobre 
quem é o aprendiz, quais são suas experiências, preferências de aprendizagem, condições de vida e trabalho, demandas e necessidades que o levaram a determinado contexto de formação.

\subsection{Níveis de EaD}

A seguir, são apresentados os diferentes níveis de EaD relacionado por MORAN (2004):

- Ensino regular com uso de tecnologias à distância - Neste tipo de ensino os alunos podem receber, independente do local onde se encontram, materiais como vídeos e programas de computador, através de satélite, redes eletrônicas ou até correios. Nele existe a comunicação de aluno com aluno, professor com professor e aluno com professor por recursos como o telefone, o computador ou o videofone, o que promove uma maior proximidade e interatividade.

- Ensino regular com tecnologias a distância substitutivas - Devido à falta de professores qualificados ou de recursos tecnológicos mais avançados, os alunos, principalmente de escolas carentes, podem receber programas, aulas e outros tipos de apoios de outras escolas mais equipadas. Este ensino é feito da seguinte forma: gravam-se com câmeras as aulas em uma escola e transmite-se ao vivo, via circuito fechado, para outra, onde os alunos poderão fazer perguntas e tirar dúvidas através de sistemas de áudio.

- Ensino regular aberto - Esta modalidade permite que parte dos cursos presenciais sejam ministrados a distância. Isto é, algumas disciplinas podem ser aplicadas por qualquer sistema de comunicação não presencial, podendo ser iniciadas com a presença de aluno e professor e terminadas sem que haja essa necessidade. Seriam as disciplinas dadas sob a forma de tutoria, onde os materiais podem ser acessados através de redes eletrônicas ou de vídeo. 
- Ensino regular à distância monitorado - São os cursos de nível médio ou superior onde o aluno recebe a orientação de um determinado professor ou tutor, que realiza o acompanhamento em períodos definidos no decorrer do curso a distância. Em algumas universidades esses cursos podem exigir a realização de aulas presenciais.

- Ensino regular à distância não monitorado - São os cursos ministrados totalmente de forma unidirecional, onde há apenas a transmissão dos assuntos através da televisão, e pressupõe-se que o aluno acompanhe as aulas e estude o suficiente para passar no teste que é aplicado ao final do processo. Como exemplo pode-se citar os Telecursos existentes no Brasil.

- Cursos livres a distância - São aqueles oferecidos como forma de atualização pessoal devido à necessidade de educação permanente $e$ utiliza-se de tecnologias de comunicação para serem transmitidos ao público, como por exemplo, através da internet e que garantem o recebimento de certificados reconhecidos no mercado. Podem variar entre todos os níveis, como o básico, o médio, o superior ou de especialização.

\subsection{Ferramentas computacionais utilizadas na EaD}

Há uma crescente inserção da tecnologia na sociedade como um todo, e claro, no ensino, isso não seria diferente. A internet já disponibiliza ambientes educacionais especialmente projetados para o desenvolvimento de cursos à distância e que vêm sendo amplamente utilizados como uma forma de auxílio ao professor, tornando-se um facilitador da aprendizagem, pois procura variar as abordagens pedagógicas para facilitar o aprendizado dos estudantes.

Com a finalidade de facilitar a auto-aprendizagem os ambientes colaborativos on-line também conhecidos como Ambientes Virtuais de Aprendizagem - AVA são recursos que servem a um propósito claro: “... desenvolver a interdependência e interaprendizagem entre pessoas que se 
agrupam por motivações e necessidades convergentes para atingir determinado objetivo, cujo alcance depende da participação e do compromisso com a realização de ações..." (Litto,formiga 2009). A autogestão, características destes ambientes, permite que o aluno reconheça 0 que é importante para a sua aprendizagem e, através da mediação dos recursos tecnológicos, da e-infraestrutura, alcance esta finalidade.

A utilização do AVA permite elaborar fluência de tecnologia, de mídia, de linguagem e de pessoas para, potencializar a criação de um espaço relacional de aceitação e convite à participação, à interação social apoiada em ferramentas, conceitos e signos (Litto,Formiga 2009). Na virtualização dos cursos de EaD.

Várias características são oferecidas em um ambiente virtual de aprendizagem: comunicação grupo a grupo, permitindo que o aluno se comunique com outros colegas de aula on-line; independência de lugar e tempo, permitindo que estudantes acessem os conteúdos dependendo exclusivamente da Internet, a organização e o controle de datas e eventos permitindo que alunos acompanhem o desenrolar das atividades, os controles de acesso e atividades, permitindo que gestores acompanhem as atividades desenvolvidas pelos alunos nestes ambientes. Além dessas características a utilização do AVA permite a disposição dos artefatos pedagógicos de prática e de avaliação, correspondentes ao ensino presencial, e que se traduzem em tarefas, exercícios, provas e participação nas diversas modalidades previstas no espaço pela tecnologia da informação e comunicação (Wei, 2009).

Dentro desse contexto, a tabela 2 apresenta algumas características de alguns softwares utilizados na educação à distância, normalmente utilizados na mediação entre professores e alunos nos encontros virtuais. 
Tabela 2: Características de Ambientes Virtuais de Aprendizagem

\begin{tabular}{|c|c|c|c|c|c|c|c|c|c|c|c|c|c|c|c|c|}
\hline & Mecanismo Ambiente & 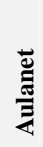 & 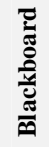 & ש๊ & 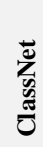 & 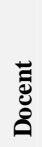 & 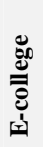 & 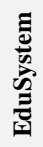 & 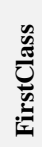 & בֶّ & 苞 & 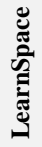 & 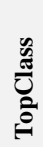 & 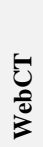 & 苋 & \\
\hline \multirow{4}{*}{ 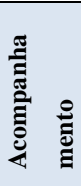 } & Rastreamento & & $\mathbf{x}$ & $\mathbf{X}$ & & $\mathbf{X}$ & $\mathbf{x}$ & $\mathbf{x}$ & $\mathbf{X}$ & $\mathbf{X}$ & & $\mathbf{X}$ & $\mathbf{X}$ & $\mathbf{X}$ & $\mathbf{X}$ & $\mathbf{x}$ \\
\hline & Redirecionamento por teste & & & & & & & $\mathbf{X}$ & & $\mathbf{X}$ & & & $\mathbf{X}$ & $\mathbf{x}$ & $\mathbf{x}$ & \\
\hline & Registros de chats & & & & $\mathbf{X}$ & & & & & & & & & $\mathbf{x}$ & $\mathbf{X}$ & $\mathbf{x}$ \\
\hline & Registros de listas & $\mathbf{x}$ & & & $\mathbf{x}$ & & & & & & & & & $\mathbf{x}$ & $\mathbf{x}$ & $\mathbf{x}$ \\
\hline \multirow{8}{*}{ 选 } & Análise de texto & & & & & & & & & & & & & & & \\
\hline & Auto-avaliação & & $\mathbf{X}$ & & & & $\mathbf{X}$ & & & $\mathbf{x}$ & & & $\mathbf{x}$ & $\mathbf{X}$ & $\mathbf{X}$ & $\mathbf{x}$ \\
\hline & Reuso de questões & $\mathbf{X}$ & $\mathbf{X}$ & & & & & & & & & & & & $\mathbf{X}$ & \\
\hline & Testes temporizados & & $\mathbf{X}$ & & & & & $\mathbf{X}$ & & $\mathbf{X}$ & & & $\mathbf{x}$ & $\mathbf{X}$ & & \\
\hline & Testes personalizados & & $\mathbf{X}$ & $\mathbf{X}$ & & & & & & & & & & & $\mathbf{x}$ & $\mathbf{x}$ \\
\hline & Testes via web & $\mathbf{X}$ & $\mathbf{x}$ & $\mathbf{x}$ & $\mathbf{x}$ & $\mathbf{X}$ & $\mathbf{X}$ & $\mathbf{x}$ & $\mathbf{X}$ & $\mathbf{x}$ & $\mathbf{X}$ & $\mathbf{X}$ & $\mathbf{x}$ & $\mathbf{X}$ & $\mathbf{x}$ & $\mathbf{x}$ \\
\hline & Testes adaptáveis & & $\mathbf{x}$ & & & & & & & $\mathbf{x}$ & & & $\mathbf{X}$ & $\mathbf{x}$ & $\mathbf{X}$ & $\mathbf{x}$ \\
\hline & Trabalhos via web & $\mathbf{X}$ & & $\mathbf{X}$ & $\mathbf{X}$ & & & $\mathbf{X}$ & $\mathbf{X}$ & & & & & $\mathbf{X}$ & $\mathbf{X}$ & $\mathbf{x}$ \\
\hline
\end{tabular}

Fonte: Silva, 2001 (adaptação)

A tabela 2 leva em consideração apenas os meios de avaliação e o tipo de acompanhamento para mostrar a eficiência de cada uma das ferramentas, no entanto ao escolher um AVA para ser utilizado como ferramenta colaborativa em uma metodologia de $\mathrm{EaD}$ não se deve esquecer de avaliar itens como: agenda, mural, disponibilização de material de apoio, glossário, notas, perfil, fórum, dentre outros que tornam o AVA mais atrativo do ponto de vista de alunos, professores e administradores de cursos. 


\section{EDUCAÇÃO NO ESTADO DO AMAZONAS}

Atualmente o Estado do Amazonas para oferecer educação de nível superior conta com uma universidade federal com sede na capital Manaus e em mais 16 núcleos no interior do Estado, uma universidade estadual presente em todos os municípios da federação e para o ensino médio conta com a Secretaria de Educação.

O Estado do Amazonas torna-se diferente dos outros estados brasileiros principalmente no que diz respeito ao clima, vegetação e sua grande extensão territorial de difícil acesso, onde os rios são na grande maioria os únicos meios de locomoção. Esses fatores juntos dificultam de forma substancial a tarefa de se promover e levar educação de qualidade aos 61 municípios do Estado.

Tentando mudar essa realidade, o governo do Estado estabeleceu no ano de 2000 metas para a educação que viessem a atender a Lei de Diretrizes e Bases da Educação Nacional: "formar professores". Criando a Universidade do Estado do Amazonas - UEA e implantando um modelo de educação inovador inicialmente para atender os profissionais da educação que já atuavam em sala de aula, mas que ainda não possuíam qualificação profissional de nível superior.

Levando-se em consideração a grande extensão territorial do Estado do Amazonas, a escassez de profissionais habilitados a atuarem na docência nos municípios, e visando ainda formar profissionais capacitados a suprirem as necessidades locais, optou-se por um modelo de educação considerado a distância que para região não é somente uma necessidade mais a única opção, mas que reunisse também todas as características do modelo tradicional presencial.

O modelo de educação adotado não só atingiu as metas estabelecidas, como também mudou a forma de se promover educação em todo Estado. 


\subsection{A Universidade do Estado do Amazonas - UEA}

A criação da Universidade do Estado do Amazonas - UEA, foi autorizada

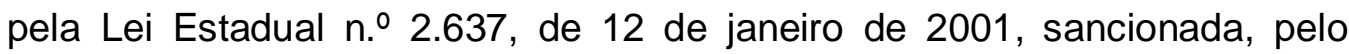
então governador Amazonino Armando Mendes. Esta Lei estabeleceu seus principais objetivos: promover a educação, desenvolvendo o conhecimento científico, particularmente sobre a Amazônia, conjuntamente com os valores éticos capazes de integrar o homem à sociedade e de aprimorar a qualidade dos recursos humanos existentes na região; ministrar cursos de grau superior, com ações especiais que objetivem a expansão do ensino e da cultura em todo o território do Estado.

A UEA criou no ano de 2001 uma forma de ensino denominada EPMRT. O primeiro curso a ser transmitido por intermédio deste sistema foi o Programa de Formação e Valorização dos Profissionais da Educação - PROFORMAR, este curso foi criado para atender a uma solicitação da Secretaria de Estado da Educação e Qualidade do Ensino, com o objetivo de cumprir os dispositivos legais da Lei de Diretrizes e Bases da Educação Nacional, que determinou a qualificação de professores obrigatória e feita em curso superior, independente do nível de ensino: fundamental ou médio. A mesma Lei estabeleceu a "Década da Educação" como tempo necessário para que todos os Estados da Federação pudessem se organizar, estabelecer programas específicos de formação de professores e profissionalizar as carreiras do magistério do ensino fundamental. Para respaldar financeiramente essas atividades foi criado o Fundo de Manutenção e Desenvolvimento do Ensino Fundamental e de Valorização do Magistério (FUNDEF), com vigência a partir de primeiro de janeiro de 1998, formado com contribuições financeiras dos Municípios e dos Estados da Federação e de contribuições do Orçamento da União como parte substancial da aplicação constitucional obrigatória para a educação a ser feita pelos entes federativos ( BARBOSA ; RAMOS, 2008).

O PROFORMAR, passados sete anos, assim, alcança os objetivos a que se propôs. Teve início em 2001, com o exame vestibular em todos os municípios do interior do Estado, e concluiu sua segunda fase em setembro 
de 2008. No dia 30 de julho de 2005, por intermédio de uma rede de TV, realizava-se a Colação de Grau de 7.150 (sete mil, cento e cinqüenta) alunos das turmas espalhadas nas 61 (sessenta e uma) sedes municipais do Estado, a maior formatura de graduação que se tem notícia, feita no mesmo dia, na mesma hora, em espaço geográfico tão disperso. As turmas da capital, com 1.690 alunos, no final do mesmo ano, chegavam ao término do curso, visto que começaram um semestre após às turmas do interior. Ainda em 2005, houve uma seleção de alunos para o PROFORMAR II, visando completar os quadros de professores licenciados nos sistemas educacionais de ensino do Amazonas.

Aproveitando-se da experiência do PROFORMAR I e II, outros programas foram criados e estão em andamento. São eles: "Licenciatura em Matemática"; "Especialização em Gestão da Educação"; "Licenciatura em Educação Física"; e Graduação em "Tecnologia em Análise e Desenvolvimento de Sistemas". Usando o sistema de Ensino Mediado pela TV, como concebido para o PROFORMAR, já foi concluído, o Bacharelado em Ciência Política, ministrado em 13 municípios para cerca de 1.500 alunos.

\section{Tabela 3: Cursos e alunos beneficiados pelo EPMRT}

\begin{tabular}{|l|r|}
\hline Cursos & Alunos Beneficiados \\
\hline Especialização em Gestão Escolar & 1.500 \\
\hline Especialização em Educação Matemática & 120 \\
\hline PROFORMAR & 16.061 \\
\hline Licenciatura em Matemática & 1.200 \\
\hline Tecnologia em Análise e Desenvolvimento de Sistemas & 380 \\
\hline Educação Fisica & 832 \\
\hline Ciência Politica & $\mathbf{7 4 8}$ \\
\hline Total & $\mathbf{2 0 . 8 4 1}$ \\
\hline
\end{tabular}

Fonte: Pró-reitoria de Graduação da UEA 


\subsubsection{Secretaria de Educação do Estado do Amazonas (SEDUC-AM)}

A criação da Secretaria de Estado de Educação e Qualidade do Ensino (Seduc) ocorreu no ano de 1946, através da Lei 1.596, de 05/01/1946, com denominação de Diretoria Geral do Departamento de Educação e Cultura. Com a Lei 12, de 09/05/1953 sofreu a primeira alteração em sua nomenclatura, recebendo o nome de Secretaria de Educação, Cultura e Saúde. Ainda no mesmo ano, com a Lei 65, de 21/07/1953, recebeu a denominação de Secretaria de Educação, Saúde e Assistência Social. Após dois anos, sob a Lei 108, de 23/12/1955, recebe o nome de Secretaria de Educação e Cultura. Nova alteração só ocorreu 46 anos mais tarde, com a Lei 2.032, de 02/05/1991, quando recebe o nome de Secretaria de Estado da Educação, Cultura e Desporto.

A denominação atual, de Secretaria de Estado da Educação e Qualidade do Ensino (Seduc) veio com a Lei 2.600, de 04/02/2000.

A SEDUC-AM além de atuar no ensino presencial regular, se aproveitou da experiência e sucesso do EPMRT implantado inicialmente na UEA, e a partir do ano de 2007 criou o Centro de Mídias (localizado na cidade de Manaus) que é o responsável pela transmissão das aulas das três séries do ensino médio, tendo como resultado inicial, 10 mil alunos em 42 municípios que puderam continuar seus estudos e cursar o $1^{\circ}$ ano do Ensino Médio em 2007 e em 2009 esses números de atendimento chegaram a 25.000 alunos de 62 municípios.

\subsection{Ensino Presencial Mediado por Recursos Tecnológicos - EPMRT}

O Sistema presencial mediado por recursos tecnológicos é um método educacional que tem como finalidade principal superar as distâncias e dificuldades de acesso existentes na região amazônica e prover ensino de qualidade. Ele consiste na transmissão de aula, a partir de um estúdio de 
televisão localizado na sede da universidade, de forma simultânea e ao vivo para todas as salas de aula geograficamente distantes, através de uma rede privada de Internet conectada via satélite, fazendo o uso de três tipos de mídia: dados, vídeo e voz:

"... se definiu o instrumento do Sistema de Ensino Presencial Mediado, fundamentado no tripé - recursos tecnológicos, pessoal devidamente qualificado e procedimentos didáticos específicos - criando, dessa feita, a ambiência comparável às salas de aula do curso presencial..." (Barbosa; Ramos, 2008).

Conforme apresentado na figura 1 os, recursos tecnológicos empregados no modelo são: estúdio de televisão que conta com estrutura apropriada; central de atendimento ao aluno com canal telefônico gratuito; e tecnologia de transmissão de aula com canal de satélite dedicado e largura de banda de 2 Mb sendo dividida em: $1 \mathrm{Mb}$ para transmissão do vídeo-aula; $512 \mathrm{~Kb}$ para acesso a Internet; e $512 \mathrm{~Kb}$ para VoIP.

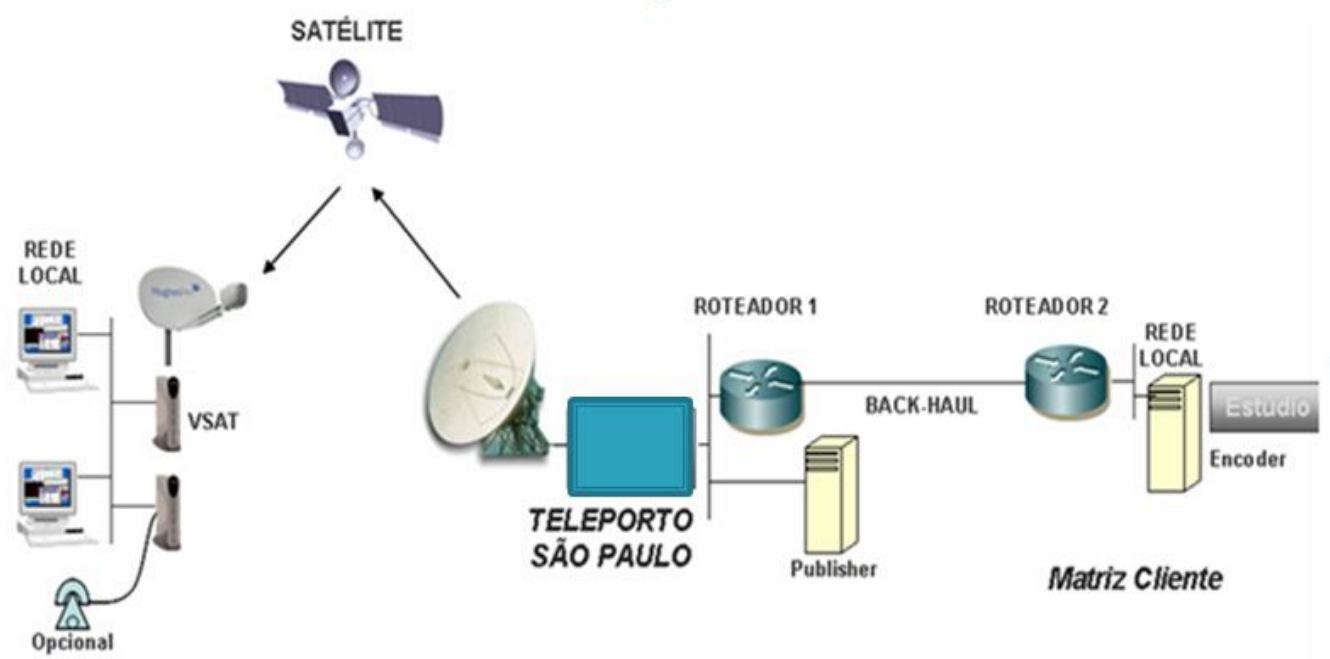

Figura 1: Modelo tecnológico utilizado no EPMRT.

Os recursos humanos envolvidos são: professores titulares, também conhecidos como professores- apresentadores que são encarregados da elaboração e ministração das aulas a partir do estúdio de televisão; professores assistentes, que acompanham os alunos de forma presencial; e 
equipe técnica de design, responsável pela transformação do material didático disponível para um padrão utilizado no meio televisivo.

Os procedimentos didáticos específicos consistem na produção de livros técnicos; e elaboração de aulas reproduzidas em textos roteirizados e slides que agregam além da descrição do conteúdo, ilustrações, fotografias e outros recursos audiovisuais. 


\section{A CONSTRUÇÃO DO CONHECIMENTO ATRAVÉS DO EPMRT}

Para que a construção do conhecimento seja alcançada através do método de ensino PMRT todos os elementos citados anteriormente precisam se relacionar. A figura 2 apresenta os processos inter-relacionados, bem como seus insumos (entradas), ferramentas e regras de negócio envolvidas, obtendo como produto final o aprendizado do aluno.

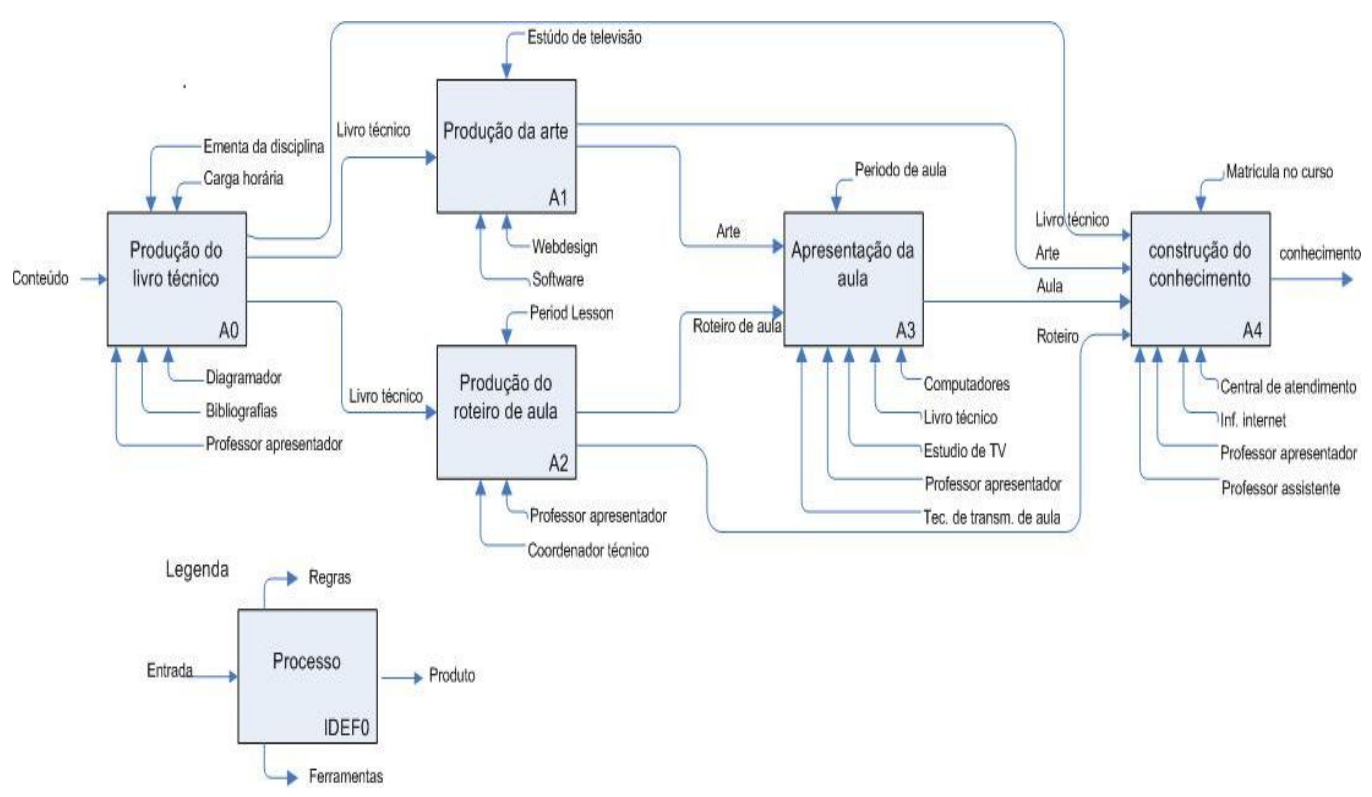

Figura 2: Processos inter-relacionados para construção do conhecimento.

O primeiro processo é a Produção do livro técnico. Esse processo consiste na definição das ferramentas: escolha de 03 (três) professores titulares, 01 (um) diagramador e diversas referências, que servem de fundamentação teórica complementar. O conteúdo programático, a carga horária e a ementa da disciplina (oriunda do plano pedagógico) são respectivamente o insumo e as regras do processo.

Além do livro que é redigido especialmente para a disciplina a ser ministrada, são adquiridos cinco bibliografias por disciplina e três exemplares 
para cada uma delas que são enviadas para cada um dos municípios que fazem parte do projeto tendo a certeza de que ao final do curso, cada município terá um acervo completo dos principais títulos de cada uma das disciplinas ministradas.

O segundo processo é a Produção da arte. Esse processo consiste na definição das ferramentas: alocação de web design e a escolha de softwares apropriados para elaboração das aulas no padrão televisivo. O livro técnico e o padrão televisivo são respectivamente o insumo e a regra deste processo. O terceiro processo é a Produção do roteiro. Esse processo possui como ferramenta o trabalho especializado do professor apresentador em conjunto com a coordenação técnica de televisão que definem a correta utilização do tempo em relação ao conteúdo a ser apresentado durante as aulas, bem como a seleção dos recursos audiovisuais apropriados. O livro técnico e o período diário reservado para as aulas (04 horas divididas em 03 tempos de 70' cada, intervalados por 15' cada tempo) são respectivamente o insumo e a regra do processo.

O quarto processo é a Apresentação da aula. Esse processo conta com as ferramentas: livro técnico, computadores, estúdio de televisão, tecnologia de transmissão de aula e o professor apresentador. Como insumo o processo conta com a arte e roteiros produzidos e como regra a correta utilização dos tempos de aula definidos na roteirização.

O quinto e último processo é a Construção do conhecimento. Como ferramenta este processo conta com a infra-estrutura de Internet, o professor apresentador, o professor assistente e a central de atendimento ao aluno. Os insumos compreendem o livro técnico, as artes, os roteiros de aula e a aula propriamente dita ministrada, a regra existente é a exigência de aluno regularmente matriculado no curso. 


\subsection{Curso de Tecnologia em Análise e Desenvolvimento de Sistemas - TADS na modalidade PMRT)}

O curso TADS foi criado no ano de 2006 com o objetivo de formar os tecnólogos em análise e desenvolvimento de sistemas para atuarem em pesquisa, gestão, desenvolvimento, uso e avaliação de tecnologias da informação aplicadas no mercado de computação e informática no interior do Estado do Amazonas.

A duração do curso é de 7 (sete) semestres, ou 42 (quarenta e dois) meses, que são equivalentes a 2040 horas no total e as aulas são ministradas cinco dias por semana, de segunda a sexta-feira, durante quatro horas por dia, e excepcionalmente aos sábados.

Este curso é destinado a candidatos aprovados através de prova de seleção (vestibular) realizada pela UEA, e é televisionado para os 12 municípios do interior do Estado do Amazonas, onde há professores qualificados para 0 ensino da Computação e Informática e inseridos na cultura local.

Por ser oferecido em municípios que ficam separados por uma grande distância, este curso é ministrado através do EPMRT e faz uso de todos os recursos que o referido sistema disponibiliza o que garante a divulgação de um ensino uniforme a todos os alunos.

Tabela 4: Municípios integrantes do curso TADS

\begin{tabular}{|c|c|c|c|}
\hline \multirow{2}{*}{ MUNICÍPIOS } & \multicolumn{3}{|c|}{ VAGAS } \\
\hline & MORADOR & INDÍGENA & TOTAL \\
\hline Boca do Acre & 30 & 2 & 32 \\
\hline Carauari & 30 & 2 & 32 \\
\hline Careiro-Castanho & 30 & 2 & 32 \\
\hline Coari & 30 & 2 & 32 \\
\hline Eirunepé & 30 & 2 & 32 \\
\hline Humaitá & 30 & 2 & 32 \\
\hline Lábrea & 30 & 2 & 32 \\
\hline Manacapuru & 30 & 2 & 32 \\
\hline Manicoré & 30 & 2 & 32 \\
\hline Maués & 30 & 2 & 32 \\
\hline Presidente Figueiredo & 30 & 2 & 32 \\
\hline São Gabriel da Cachoeira & 30 & 2 & 32 \\
\hline $\begin{array}{c}\text { TOTAL } \\
\end{array}$ & 360 & 24 & 384 \\
\hline
\end{tabular}




\subsection{Componentes do curso TADS}

O curso de Tecnologia em Análise e Desenvolvimento de Sistemas -TADS na modalidade PMRT, está vinculado a uma das unidades da Universidade do Estado do Amazonas, à Escola Superior de Tecnologia, no entanto o memso é dotado de uma estrututra independente administrativa (com subordinação acadêmica a Pró-reitoria de graduação) capaz de prover agilidade de execução nas mais diversas tarefas desde a seleção e contratação de pessoal (diagramadores, professores, entre outros), licitações para contratação de empresas para prestação de serviços (impressão gráfica, transmisão de aula), aquisição de material de consumo, até a compra de equipamentos, contando para isso com uma equipe de gerência de projetos constituida pela corrdenação pedagógica, responsável por todo o processo acadêmico incluindo seleção de professores, supervisão na produção do livro técnico, definição de conteúdo programático das disciplinas, supervisão durante a apresentação das aulas, acompanhamento no atendimento ao aluno, correção e divulgação de notas, dentre outras atividades, já a cordenação de técnologia administrativa educacional é responsável por todas as atividades administrativas, financeiras e tecnológicas como, contratação de pessoal, aquisição de material e equipamentos, logística para transporte de pessoal e material, definição de tipos de equipamentos para aquisição até definição de critérios para contratação de empresa para produção e transmissão de aula. A figura 3 dá uma visão de todos os componentes e processos do curso divididos em gerência de projetos, produção pedagógica, aquisições, infra-estrutura e distribuição (logística). 


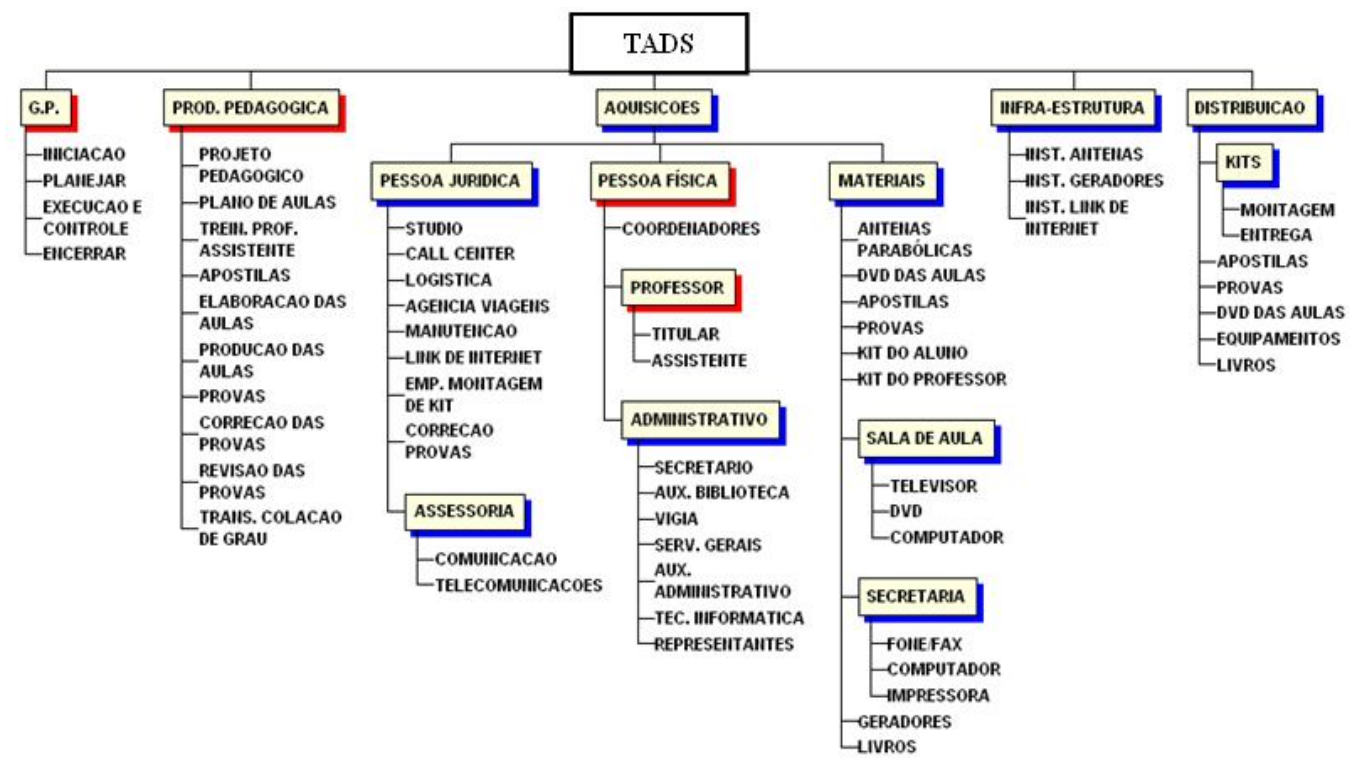

Figura 3: Visão dos componentes do curso TADS

\subsection{Equipamentos}

Os recursos e os procedimentos, utilizados no sistema de ensino presencial mediado, formam um ambiente que recria as características da aula presencial favorável ao desenvolvimento dos processos de aprendizagem, com a utilização dos seguintes equipamentos:

- Em Manaus: Um estúdio completo de televisão e uma Central de Atendimento (Call Center).

- Em cada núcleo da Universidade em cada município: uma antena VSAT, uma impressora laser conectada em rede, um gerador de energia, um laboratório com computadores conectados a internet.

- Em cada sala de aula: um televisor, fax, computador conectado a internet, aparelho para gravação de aula. 


\subsection{Pessoal}

O curso de Tecnologia em Análise e Desenvolvimento de Sistemas - TADS é dotado da seguinte equipe: coordenação geral do curso, coordenação pedagógica e coordenação de tecnologia administrativa educacional cuja função é coordenar e supervisionar todo o Sistema do curso com as atribuições de:

- Selecionar professores;

- Organizar a programação de cada período, com a antecedência necessária ao bom andamento do curso;

- Providenciar, junto aos professores e responsáveis titulares, a definição dos textos relativos aos manuais das disciplinas, a aquisição do acervo bibliográfico, os equipamentos de apoio didático e as condições de funcionamento das salas;

- Providenciar, para cada disciplina, o material de apoio necessário ao desenvolvimento das atividades em sala de aula;

- Acompanhar o processo de produção do material gráfico;

- Encaminhar processos relativos a aproveitamento de estudos, transferências de turmas, ao setor de controle acadêmico da Universidade e manter os alunos informados dos processos de seus interesses;

- Preparar Planos de Orientação Pedagógica;

- Acompanhar a distribuição de materiais e logística do projeto;

\subsection{Experimentos de Ferramentas computacionais de suporte}

Computação Cooperativa ou Computer-Supported Cooperative Work (CSCW) é o uso de sistemas computacionais que suportam grupos de indivíduos trabalhando para realização de um objetivo comum e que deve possuir interfaces multi-usuários, controles de concorrência, comunicação e coordenação e suporte a ambientes heterogêneos. A CSCW possibilita uma 
comunicação mais rápida, ampla e eficiente, e introduz um grande número de novos recursos para serem explorados pelos indivíduos através do computador.

Lohuis (2006) afirma que a interação social realizada pelo trabalho em grupo, assim como o fato dos indivíduos atuarem nos grupos, compartilhando idéias, informações, responsabilidades, decisões, são imprescindíveis ao desenvolvimento operatório do ser humano.

Deste modo, o uso da tecnologia aliada às práticas de cooperativismo que a CSCW prega, é visto como uma excelente forma de se oferecer a EaD em um nível bastante elevado, pois a interação entre alunos e professores seria uma ótima forma de promover não só a troca de conhecimentos como também uma boa relação entre os envolvidos.

\subsubsection{AVA como ferramenta auxiliar no EPMRT}

Os alunos de um curso do Ensino Presencial Mediado por Recursos Tecnológicos contam com toda infra-estrutura física e tecnológica das salas de aula, mas ainda sim o processo de aprendizado se ressente do convívio diário e da troca de experiência teórica e social proveniente do contato aluno-aluno e aluno-professor. Isto acontece porque, alunos do mesmo curso, mas de salas de aulas geograficamente distantes não contam com meios de comunicação que proporcionam um ambiente cooperativo entre eles e entre os professores apresentadores, detentores de grande parte do conhecimento teórico das disciplinas ofertadas.

O curso de Tecnologia em Análise e Desenvolvimento de Sistemas (TADS), oferecido pela universidade na modalidade PMRT, realizou uma experiência a partir do ano de 2008, ao disponibilizar no seu portal um ambiente cooperativo para seus alunos. Para isto foi escolhido o software Modular Object Oriented Distance Learning (Moodle), pois o mesmo já vem sendo utilizado pela maioria das universidades federais que fazem parte do programa de educação à distância do governo federal 'Universidade Aberta do Brasil - UAB'. 
O ambiente virtual de aprendizagem foi adaptado ao EPMRT para dar o apoio suplementar esperado tornado-se muito mais que um espaço de comunicação. Este ambiente possibilitou superar inúmeras dificuldades vivenciadas pelos alunos, entre as mais importantes está o acesso aos objetos educacionais desenvolvidos durante a construção do conhecimento (aulas, roteiros slides, textos de apoio, programas-exemplos, programasexercícios, ferramentas de estudo, e outros recursos digitais típicos de um curso de Tecnologia da Informação e Comunicação como é da natureza do TADS).

Além do acesso irrestrito a estes objetos, o ambiente ofereceu a troca de mensagens, a promoção da construção do conhecimento através de fóruns de discussão, informações sobre a disciplina e sobre as ferramentas utilizadas, e debates virtuais além de cursos de extensão, palestras, avisos, calendários e informações sobre professores apresentadores e alunos.

Outras experiências foram possíveis ao utilizar o AVA não apenas como instrumento de apoio ao processo ensino-aprendizagem como também foi possível promover a socialização entre alunos que puderam disponibilizar fotos, informações pessoais, detalhes do município, da cultura local, tornando o ambiente mais universal e atraente.

Como é conhecido o conceito de transposição que diz respeito a mudar de lugar no sentido de transpor a aula ou atividades presenciais para ambiente virtual, o AVA para o EPMRT transpôs inversamente ao oferecer o ambiente presencial das universidades em um ambiente tecnológico e virtual sobre o qual o Sistema Presencial Mediado por Recursos Tecnológico foi criado. Como exemplo os professores apresentadores ao terminarem as aulas no estúdio passavam a conversar e atender dúvidas e discussões através dos meios de mensagens e comunicações próprios do AVA, proporcionando, uma nova forma de contato com o professor e assim permitindo um aprimoramento das suas experiências. Como cada disciplina do EPMRT possui 03 (três) professores apresentadores, o atendimento ao aluno é feito várias vezes ao dia, por vários professores em conjunto ou isoladamente, mantendo sempre o aluno envolvido nas atividades da disciplina. 


\subsubsection{Metodologia de avaliação do AVA}

Um questionário foi desenvolvido para avaliar a eficiência do ambiente virtual de aprendizagem, como ferramenta de apoio ao EPMRT nas áreas pedagógica e social. Para isto foram elaboradas 09 questões objetivas e disponibilizadas para os 12 municípios do curso TADS envolvendo 248 (duzentos e quarenta e oito) alunos. O questionário foi disponibilizado de duas formas aos alunos: através de questionário eletrônico no próprio AVA por um período de três semanas e através de documento físico através dos professores assistentes.

Devido às características geográficas da região amazônica, onde, em muitos casos, o acesso a Internet só acontece via satélite, os alunos dispuseram de três meios para responder ao questionário: na primeira forma os alunos utilizaram a Internet disponível nos laboratórios dos núcleos universitários distribuídos pelos municípios. Na segunda forma os alunos trabalharam offline, e enviaram através do software utilizado na transmissão de dados durante as aulas; e na terceira forma os alunos acessaram o AVA, por exemplo, através de lan-houses e responderam ao questionário ou o enviaram através de seus e-mails. Estes formulários foram reunidos e as informações apresentadas na tabela 5. 
Tabela 5: Resultados obtidos na avaliação do AVA

\begin{tabular}{|c|c|c|c|}
\hline Questão & Resposta & Votos & Percentual \\
\hline \multirow{2}{*}{1} & $\mathrm{Sim}$ & $37 / 248$ & $14,9 \%$ \\
\hline & Não & $211 / 248$ & $85,1 \%$ \\
\hline \multirow{2}{*}{2} & Sim & $202 / 248$ & $81.5 \%$ \\
\hline & Não & $46 / 248$ & $18,6 \%$ \\
\hline \multirow{3}{*}{3} & $\mathrm{Sim}$ & $123 / 248$ & $49,6 \%$ \\
\hline & Não & $38 / 248$ & $15,3 \%$ \\
\hline & As vezes & $87 / 248$ & $35,1 \%$ \\
\hline \multirow{5}{*}{4} & Chat & $63 / 532$ & $11,8 \%$ \\
\hline & Fórum & $66 / 532$ & $12,4 \%$ \\
\hline & Exercicios & $153 / 532$ & $28,8 \%$ \\
\hline & Noticias & $143 / 532$ & $26,9 \%$ \\
\hline & Calendário & $107 / 532$ & $20,1 \%$ \\
\hline \multirow{2}{*}{5} & Sim & 2257248 & $90,7 \%$ \\
\hline & Não & $23 / 248$ & $9,3 \%$ \\
\hline \multirow{4}{*}{6} & Péssima & $37 / 248$ & $14,9 \%$ \\
\hline & Regular & $81 / 248$ & $32,7 \%$ \\
\hline & Boa & $98 / 248$ & $39,5 \%$ \\
\hline & Ótima & $32 / 248$ & $12,9 \%$ \\
\hline \multirow{3}{*}{7} & Piorou & $19 / 248$ & $7,7 \%$ \\
\hline & Não mudou em nada & $53 / 248$ & $21,4 \%$ \\
\hline & Melhorou consideravelment & $176 / 248$ & $71,0 \%$ \\
\hline \multirow{2}{*}{8} & Sim & $35 / 248$ & $14,1 \%$ \\
\hline & Não & $213 / 248$ & $85,9 \%$ \\
\hline \multirow{5}{*}{9} & Menor que 3 & $9 / 248$ & $3,6 \%$ \\
\hline & entre 3 e 5 & $14 / 248$ & $5,7 \%$ \\
\hline & entre 6 e 7 & $52 / 248$ & $21,0 \%$ \\
\hline & entre 8 e 9 & $77 / 248$ & $31,1 \%$ \\
\hline & a nota é 10 & $96 / 248$ & $38,7 \%$ \\
\hline
\end{tabular}

Como apresenta a questão 1: A ferramenta Moodle pode substituir a explicação do professor assistente dentro do laboratório? 14.92\% dos alunos dispensam a presença do professor assistente no laboratório de informática quando da realização das atividades práticas do curso de análise e desenvolvimento de sistemas. $85.08 \%$, ou seja, 211 alunos acham que o professor assistente precisa acompanhá-los nas aulas práticas e ajudam a dissipar as dúvidas que surgem durante as atividades práticas.

$\mathrm{Na}$ questão 2: Melhorou seu desempenho na graduação? 202 alunos, $81.45 \%$, acreditam que o desempenho nas disciplinas do curso melhorou devido à utilização de uma ferramenta de apoio sócio-técnico. Apenas $18.55 \%$ dos alunos consultados não descrevem melhorias no seu desempenho. 
A questão 3: Costuma com frequência acessar a ferramenta Moodle e o TADSVirtual? O TADSVirtual é o nome pelo qual o ambiente virtual de aprendizagem é conhecido pelos alunos e professores. $49.60 \%$ dos alunos responderam que sim, acessam com frequência o AVA, $35.08 \%$ responderam que somente às vezes podem acessar o recurso. Somente $15.32 \%$ dos alunos, ou seja, 38 alunos, responderam que não buscam o ambiente durante as aulas.

Na questão 4: Qual recurso você mais utiliza no site? Vários recursos foram testados e avaliados pelos alunos do curso: chat, fórum, exercícios, notícias e calendários. Eles poderiam escolher 1 (um) ou mais recursos que thes agradassem e fossem importantes para melhora do seu desempenho. $O$ resultado demonstra que os alunos utilizam mais de um recurso durante os acessos ao AVA. Os mais requisitados foram os exercícios e notícias do curso e das disciplinas que são postados no ambiente. Eles recebem 153 $(28,76 \%)$ e $143(26,88 \%)$ votos respectivamente. A seguir o calendário do curso e das disciplinas, com datas importantes para o aluno, que atestou em entrevistas complementares ao questionário, produzir sua própria agenda de compromissos, recebeu $107(20,11 \%)$ votos. Por último, mas não menos importante o fórum e chat com $66(12,41 \%)$ e 63 (11,84\%) votos respectivamente.

A questão 5: Compartilha informações com alunos de outros municípios onde o curso é oferecido? 225 alunos, ou seja, 90.73\% conversam e trocam experiências com colegas do mesmo curso, mas que estudam e residem em municípios distantes. A diferença, 9.27\% não pratica esta experiência.

$\mathrm{Na}$ questão 6: Como você classifica a interatividade entre alunos e professores no curso TADS antes da implantação da ferramenta? O questionário refere-se ao professor-apresentador, que fica no estúdio de televisão durante as aulas. $39,52 \%$ dos alunos consideram boa a interatividade entre as partes; apenas $12.90 \%, 32$ alunos consideram ótima esta interatividade. $32.66 \%$, ou seja, 81 alunos não estavam satisfeitos e consideram regular o canal de interação e 37 alunos, $14.92 \%$ classificavam como péssima. 
Na questão 7: Depois da implantação do TADSVirtual a interatividade melhorou? $70.97 \%$ consideram uma melhora considerável na interatividade entre o professor-apresentador e o aluno. $21.37 \%$ não viram alterações na interação e $7.66 \%$ acham que o canal piorou.

Na questão 8: Acha complicada a manipulação da ferramenta Moodle implantada no ambiente virtual de aprendizagem? Como alunos de um curso de tecnologia, 213 alunos, 85.89\% responderam que não consideram complexo o uso da ferramenta. Apenas 35 alunos, 14.11\% consideram a ferramenta complicada.

Na questão 9: Qual nota você atribui a ferramenta MOODLE / TADSVirtual para o processo ensino aprendizagem do TADS? $38.71 \%$ dos alunos classificam a ferramenta com a nota máxima, ou seja, $10.31 .05 \%$ dos alunos, ou seja, 77 alunos, classificam a ferramenta com notas variando no intervalo entre 8 e $9.20 .97 \%$ dos alunos, classificam a ferramenta com notas variando entre 6 e 7, 14 alunos, 5.65\% classificam a ferramenta com notas variando no intervalo entre 3 e 5 e finalmente, 9 alunos, $3.63 \%$, classificaram a ferramenta com nota menor que 3 .

\subsubsection{A Importância do AVA no EPMRT}

Pelo resultado apresentado é certo que a utilização de um ambiente virtual de aprendizagem garantiu uma aproximação entre os diversos atores do Sistema Presencial Mediado por Recursos Tecnológicos. Durante as semanas em que os formulários estavam sendo respondidos e enviados vários questionamentos foram feitos pelos alunos, no sentido de entender a pergunta e justificar a escolha de uma alternativa como resposta. A questão da disponibilidade da Internet além do período das aulas (principalmente nos laboratórios) foi o maior fator de críticas ao modelo, o que pode ser observado nas respostas dos alunos.

Vários pontos positivos foram incorporados na rotina do EPMRT trazendo uma melhor compreensão para os papeis do professor assistente, professorapresentador, alunos e coordenadores do curso. 
- O professor assistente passou a receber artefatos de disciplinas através do AVA, de forma rápida e organizada. O contato com professores-apresentadores da disciplina favoreceu o entendimento do conteúdo técnico, do prévio entendimento das avaliações, exercícios e suas resoluções.

- O professor-apresentador passou a atender alunos e professores assistentes através dos meios de comunicação do AVA, reduzindo as chamadas do call-center no estúdio. Além disso, o professorapresentador ampliou sua carga horária regular de trabalho e de atendimento ao aluno ficando presente no AVA em períodos previamente determinados. Além de todos os artefatos de aula, definidos inicialmente no EPMRT, o professor-apresentador passou a construir e dispor de outros objetos educacionais, ferramentas extras de aula, debates educacionais, mantendo o ambiente sempre inovador e motivador para o aluno.

- Os coordenadores de curso passaram a acompanhar a evolução do ensino, a ascensão do AVA como meio social dos alunos, o incremento das notícias e cronogramas de aula, trabalho e atividades extras, a participação do professor-apresentador e seus horários de atendimento, e principalmente, as dúvidas dos alunos, que passaram a chegar através deste canal direto, e não apenas através do professor assistente.

- O aluno dispôs do AVA como instrumento social, como a construção de blogs, o envio de mensagens e a busca de notícias sobre o curso, disciplina, materiais de extensão, entre outros. Passou a conhecer e interagir com coordenadores e professores-apresentadores, igualando ou tentando aproximar a relação construída entre eles e seus professores assistentes. $\mathrm{O}$ acesso a artefatos e objetos educacionais passou a ser direto, o que melhorou sensivelmente a disposição do aluno sua motivação em acompanhar e realizar as atividades das disciplinas. 
A experiência apresenta ainda um fator relevante como produto da utilização do AVA: a socialização dos elementos humanos do EPMRT, pois sem a utilização do mesmo não havia esta característica, que não pode ser avaliada isoladamente, mas agregada de valores sociais como: a independência, a comunicação, a universalização do conhecimento e recursos, a organização de atividades e horários, entre outros, ressaltando a natureza sócio-técnica o modelo de educação PMRT.

\subsection{Experimentos de Infra-estrutura mínima de equipamentos em sala de aula}

Desde a implantação do modelo PMRT, a forma como as aulas são transmitidas bem como os recursos tecnológicos utilizados já sofreram modificações, o experimento realizado em sala de aula visa melhorar o processo de aprendizagem propondo modificação no modo como os meios tecnológicos são utilizados.

Em cada sala, os alunos assistem às aulas em uma disposição tradicional, com o televisor em uma posição central imitando a presença do professor em sala como mostra a figura 4, no entanto, essa disposição apresenta problemas que prejudicam os alunos durante as aulas no que diz respeito ao bom entendimento dos assuntos ministrados, pois, obriga que o televisor esteja em uma posição elevada e o nível do volume de som alto, favorecendo os alunos que se encontram no final da sala e prejudicando aqueles que estão mais próximos. Outro fator prejudicial ao processo de aprendizagem está relacionado ao momento reservado para interatividade visual e através de mensagens instantâneas, pois com uma única televisão um aluno que pretende fazer um questionamento a respeito do assunto ministrado só pode fazê-lo quando outro terminar, já a interatividade através de vídeo conferência só pode ser feita do professor para com a turma como um todo e o aluno que pretende expressar sua opinião tem que ir até os equipamentos (câmera e microfone) que também estão dispostos próximos 
ao aparelho de televisão no centro da sala, causando atrasos e com isso desperdiçando o tempo reservado para interatividade.
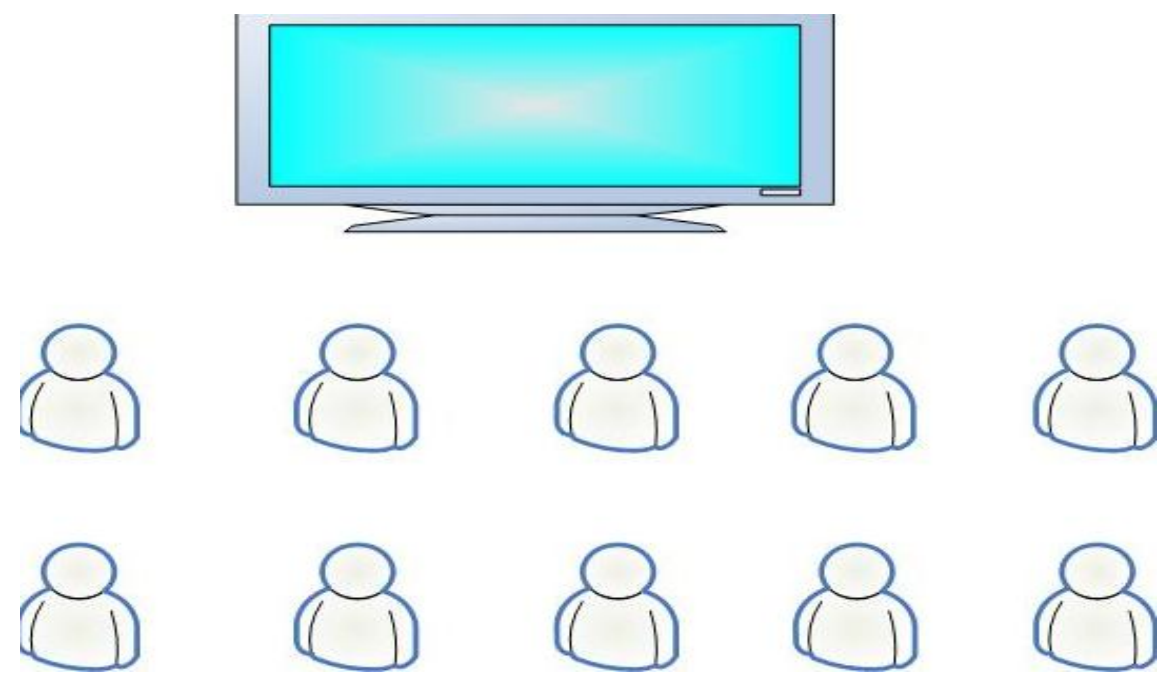

Figura 4: Disposição dos alunos em sala de aula

Em um dos municípios foi realizado um experimento para melhorar o processo de aprendizagem modificando para isso a maneira como os alunos assistem às aulas e ao invés de uma única televisão situada em uma posição central na sala de aula, uma sala foi equipada com computadores conectados a uma rede sem fio com microfone e câmera de vídeo e, uma vez que as aulas chegam ao local através de uma rede conectada via satélite em formato de arquivo, os alunos podem cada um em um computador, figura 5, assistir as aulas de forma simultânea e ao vivo da mesma forma anterior e com a possibilidade de fazerem reproduções da mesma aula em momentos distintos, permitindo que cada um possa assistir um mesmo trecho de aula mais de uma vez. 

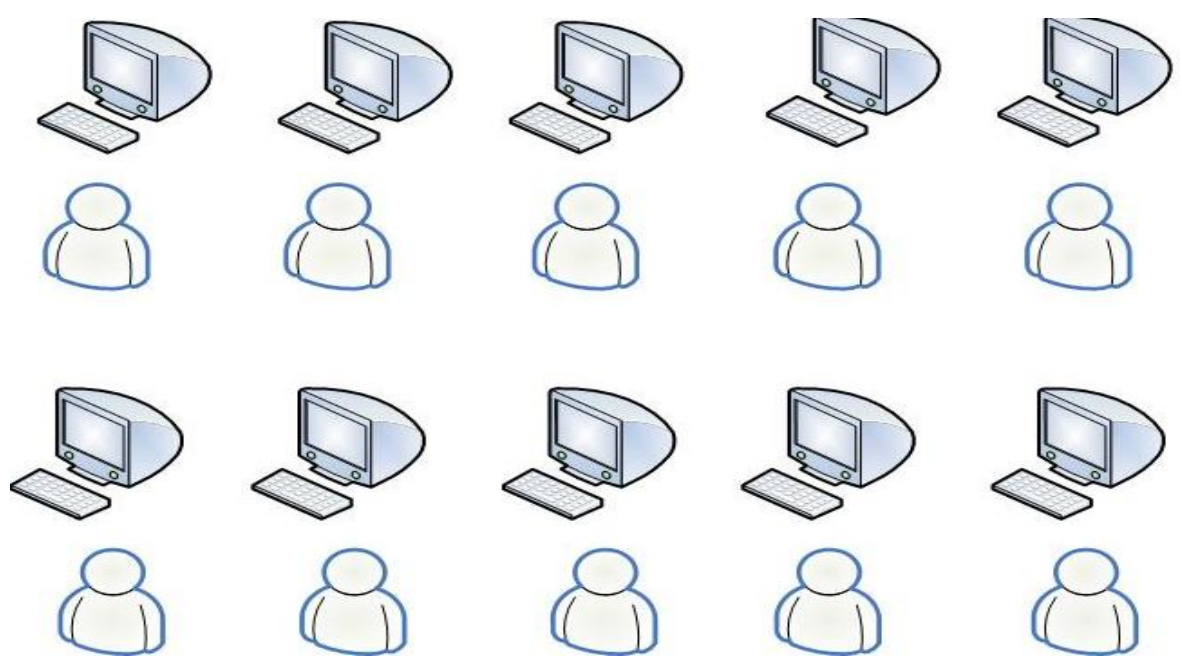

Figura 5: Disposição dos alunos em sala de aula com uso do computador

\subsubsection{Fatores relevantes observados durante o experimento}

Além dos benefícios advindos a partir das mudanças feitas em sala de aula com a substituição da televisão pelos computadores de uso pessoal, outros aspectos devem ser ressaltados:

- No momento da interatividade via chat, como os alunos estão cada um utilizando um computador, eles podem enviar suas mensagens de forma simultânea, pois as mesmas passam a entrar em uma fila de atendimento.

- Na videoconferência os alunos além de terem a comodidade de interagir do próprio computador que estão utilizando, também podem utilizar anotações digitais e trechos da própria aula ministrada para expressar de forma mais clara seus questionamentos.

- Como a aula está em um formato de vídeo que permite qualquer software reproduzi-la, o aluno passou a ter a possibilidade de gravar essa aula em uma mídia particular e levá-la para assisti-la em um momento posterior. 
- A possibilidade de ter a aula gravada em uma mídia particular facilitou a realização da prática dos exercícios que geralmente são feitos em laboratório por parte dos alunos e o assessoramento prestado pelo professor assistente, pois permitiu no momento da prática assistir ao trecho da aula em que o professor titular comenta a respeito do tema.

- As disciplinas no TADS são ministradas em módulos que duram em média 21 dias e de posse da aula que foi ministrada cada aluno pôde montar um acervo particular de cada disciplina, permitindo em determinados momentos assisti-las com o objetivo de sanar dúvidas ou revisar conceitos, importantes para a disciplina hora estudada.

- A transmissão é feita de forma simultânea para 12 salas de aula em municípios diferentes e assim permite que fatores externos possam interferir na aprendizagem dos alunos, pois um fato qualquer que interrompa a transmissão da cidade onde o estúdio de televisão está afeta a todos os municípios, no entanto, fatos isolados como falta de energia elétrica, mal tempo ou quebra de equipamentos em um único município podem deixá-lo isolado e sem receber a transmissão, mas no momento em que é sanado o problema e restabelecida a transmissão, pode-se fazer um upload da aula para o computador que pertence à rede e que está no município e disponibilizá-la para que $o$ aluno possa obtê-la.

Assim o experimento de fato contribuiu para propor uma nova maneira de utilização dos recursos tecnológicos disponíveis tanto de equipamentos individuais quanto as mídias utilizadas no modelo, sempre com o propósito de melhorar a aprendizagem. 


\section{COMPARAÇÃO ENTRE OS MODELOS DE ENSINO}

O Ensino Presencial Mediado por Recursos Tecnológicos é um modelo híbrido que apresenta características tanto do Ensino Presencial como do Ensino a Distância, a seguir são mostradas as principais características do EPMRT em relação aos outros modelos.

\subsection{Questões relacionadas a professores}

Professores apresentadores (titulares): No EPMRT as disciplinas são ministradas por uma equipe de três professores que são previamente selecionados e treinados para atuarem no modelo que vai desde a confecção do livro técnico, roteirização das aulas até a apresentação da aula propriamente dita, enquanto que no EP apenas um professor é encarregado dessa tarefa, já no EaD esse número de professores é indefinido.

No EPMRT existe ainda um professor denominado assistente, que é o responsável pelo acompanhamento das atividades acadêmicas e administrativas dos alunos em cada município, é este professor quem aplica e corrige as provas realizadas pelos alunos, acompanha as aulas práticas em laboratório, faz o controle das freqüências, dentre outras atividades. No EP não existe a figura do professor assistente, pois todas as atividades são desenvolvidas pelo próprio professor que ministra as aulas, já no EaD, existe um tutor em cada pólo que orienta e auxilia os alunos no acesso aos conteúdos disponibilizados nos ambientes virtuais pelos professores responsáveis pelas disciplinas.

\subsection{Questões relacionadas a alunos}

O atendimento ao aluno é uma tarefa que é realizada em cada sala de aula no EPMRT, pelo professor assistente, que acompanha os alunos em sala de aula e os auxilia nas atividades acadêmicas, fato este que caracteriza o 
modelo como presencial, além do atendimento feito no local onde o aluno assiste às aulas, a equipe de professores apresentadores (titulares) prestam atendimento via chat em um ambiente virtual de aprendizagem em horários pré-estabelecidos, podendo o aluno ter mais de um atendimento diário, já no EP esse atendimento é feito pelo próprio professor que está ministrando a disciplina e no EaD os tutores em cada pólo fazem as orientações devidas, mais essa tarefa é do professor que está ministrando a disciplina em um ambiente virtual de aprendizagem.

Quanto ao rendimento nos estudos, no EPMRT quando um aluno não atinge um coeficiente pré-estabelecido pelo projeto pedagógico do curso para ser considerado aprovado na disciplina, o mesmo é obrigado a cumprir uma atividade denominada "plano de estudos", que consiste em assistir novamente todas as aulas ministradas (que estão disponibilizadas em mídia) e ser acompanhado em seus estudos pelo professor assistente nas práticas e resoluções dos exercícios e ao término dessa atividade, ser submetido novamente a uma nova avaliação, no EaD o aluno refaz o módulo ou em alguns casos ele somente tem acesso a um novo conteúdo da disciplina quando cumpre determinados critérios que o tornam apto a passar para a próxima etapa, já no EP o aluno é obrigado na grande maioria a refazer a disciplina, criando assim o que hoje é chamado de "dependência".

\subsection{Questões relacionadas às disciplinas}

A apresentação das aulas no EPMRT é feita ao vivo em horários préestabelecidos, o mesmo acontece no EP onde as aulas tem hora e dia para acontecer, já no EaD, as aulas são disponibilizadas em ambientes virtuais de aprendizagem e os horários e dias para acesso são livres.

As disciplinas no EPMRT são ministradas em módulos de tal forma que somente uma disciplina é ministrada por vez, isto se deve ao fato de que para cada disciplina uma equipe de três professores é disponibilizada e se em um período de seis meses cinco disciplinas são oferecidas, seriam necessários quinze professores simultaneamente, já no EP quanto no EaD o 
tempo de duração de cada disciplina pode durar todo o período e mais de uma disciplina pode ser oferecida por vez.

Já o material didático utilizado no EPMRT é composto pelo roteiro de aula que é o documento distribuído a todos os alunos e professores envolvidos na disciplina corrente, nele estão contidas todas as informações como, horário de início e término de cada tempo de aula bem como o conteúdo que será ministrado juntamente com os meios visuais utilizados como filmes, transparências, animações e o tempo de duração de cada um, além do roteiro, um livro é produzido especialmente para cada disciplina e a própria aula ministrada no formato de vídeo juntamente com as transparências utilizadas são disponibilizadas ao aluno no ambiente virtual de aprendizagem, já na EaD, quase todo o material didático é disponibilizado no ambiente virtual de aprendizagem, podendo o aluno receber ainda apostilas e vídeos pré-gravados, o que não acontece no EP, pois o material didático disponibilizado é de inteira responsabilidade do professor que ministra as aulas em geral sem a obrigação de fazê-lo.

Quanto a questão interatividade, como a aula no EPMRT é transmitida através de uma rede IP conectada via satélite, existem momentos durante a apresentação da mesma em que os alunos podem interagir através de vídeo conferência com os professores que estão no estúdio de televisão e com os outros alunos que se encontram em salas de aula em municípios diferentes, já no EP, a interatividade entre alunos e professores acontece a todo instante, pois os mesmos encontram-se no mesmo ambiente, o que não ocorre com $0 \mathrm{EaD}$, pois, alunos e professores estão em locais e horários diferentes e a comunicação entre ambos se dá através de vídeos previamente gravados, via chat ou nos encontros presenciais.

O ítem cumprimento da carga horária e conteúdo programático no EMPRT é garantido a partir do momento em que uma disciplina é ministrada por três professores o que diminui substancialmente a possibilidade de não haver aula por falta do mesmo, além disso, como a aula é ministrada em um estúdio de televisão, o cumprimento irrestrito do horário e do que foi previsto previamente no roteiro de aula garantem que o conteúdo previsto para ser 
ministrado no dia, realmente o será, no EaD esse controle também é feito sistematicamente pois os conteúdos disponibilizados seguem critérios bem definidos de acompanhamento que na grande maioria é feito não somente pelo professor ministrante da disciplina mais por uma equipe pedagógica, já no EP o cumprimento da carga horária e conteúdo programático são de controle unicamente do professor que está ministrando a disciplina.

Quanto ao reaproveitamento de aulas e material didático, no EP um professor ao ministrar uma disciplina pela primeira vez deve elaborar seu plano de ensino definindo métodos de avaliação, bibliografia elementar e disponibilizar material de estudo a partir de sua experiência prévia em relação a disciplina, já no EaD e no EPMRT todo material didático pode ser reaproveitado tendo com isso que fazer alterações que se fizerem necessárias visando o aprimoramento da disciplina.

\subsection{Questões administrativas}

No quesito logística, todos os modelos de educação implantados na região amazônica, são extremamente prejudicados, pois, a logística utilizada é um dos maiores obstáculos, uma vez que nessa região, as vias de acesso aos municípios se dão na grande maioria através de rios, em alguns casos levando mais de quinze dias para se chegar a um município saindo de barco da capital Manaus.

Quanto ao tópico duração de um curso de graduação no EPMRT é equivalente ao tempo previsto para um curso nas modalidades presencial $\mathrm{e}$ a distância, com mesmo conteúdo programático e carga horária de disciplinas.

Para que um curso na modalidade PMRT aconteça, é necessário uma estrutura mínima de pessoal, equipamentos e serviços especializados, como contratação de empresa para prestar o serviço transmissão de aulas, pessoal de produção de mídia e estúdio de televisão, aquisição de computadores com softwares específicos que são utilizados durante as aulas, dentre outros, já no EP, aproveita-se da própria estrutura existente 
nas escolas e universidades, quanto ao $\mathrm{EaD}$, é necessário um local equipado com computadores com acesso a internet denominado "pólo" e uma equipe de produção de mídia que fica no local de onde é disponibilizado o material didático.

Quanto ao público beneficiado, tanto no EPMRT quanto no EaD, como as aulas são ministradas uniformemente para mais de uma turma em municípios distintos, o número de alunos beneficias é determinado pelo objetivo que se pretende atingir, já no EP, fica limitado ao espaço físico das salas de aula.

A tabela 6 mostra um resumo dos quesitos comparados entre os três modelos de ensino, vale ressaltar que a coluna respectiva ao EPMRT, está sempre de acordo com a coluna do EP ou do EaD, isso se deve ao fato de que EPMRT é considerado tanto presencial quanto a distância, herdando as características dos dois modelos.

Tabela 6: Comparação entre os modelos de ensino

\begin{tabular}{|c|c|c|c|}
\hline \multirow[b]{2}{*}{ Quesito } & \multicolumn{3}{|c|}{ Modalidade de ensino } \\
\hline & EPMRT & EP & $\mathrm{EaD}$ \\
\hline Professores apresentadores (ministram aula) & $\operatorname{sim}$ & $\operatorname{sim}$ & não \\
\hline $\begin{array}{l}\text { Professores assistentes (acompanham os alunos em atividades extra- } \\
\text { classe) }\end{array}$ & $\operatorname{sim}$ & não & não \\
\hline Atendimento ao aluno (presencial e via web) & sim & parcial & parcial \\
\hline Plano de estudos & $\operatorname{sim}$ & sim & não \\
\hline Apresentação das aulas ao vivo & sim & sim & não \\
\hline $\begin{array}{l}\text { Material didático utilizado (livros feitos especialmente para a disciplina, } \\
\text { trasparências, roteiros de aula, videos das aulas ministradas) }\end{array}$ & sim & não & parcial \\
\hline Interatividade & $\operatorname{sim}$ & sim & parcial \\
\hline Cumprimento da carga horária e conteúdo programático & sim & $\operatorname{sim}$ & sim \\
\hline Reaproveitamento de aulas e material didático & $\operatorname{sim}$ & parcial & $\operatorname{sim}$ \\
\hline $\begin{array}{l}\text { Acervo bibliográfico (livros adquiridos especialmente para a disciplina } \\
\text { corrente) }\end{array}$ & $\operatorname{sim}$ & não & não \\
\hline Logística cara & sim & não & $\operatorname{sim}$ \\
\hline Investimentos em infra-estrutura & $\operatorname{sim}$ & não & $\operatorname{sim}$ \\
\hline Local pré-definido para assistir aula & sim & $\operatorname{sim}$ & não \\
\hline Aulas diárias & sim & $\operatorname{sim}$ & กล̃o \\
\hline Uso das TICs & sim & não & $\operatorname{sim}$ \\
\hline $\begin{array}{l}\text { Conhecimento prévio para utilização de recursos tecnológicos } \\
\text { (computadores, internet dentre outros) }\end{array}$ & sim & não & $\operatorname{sim}$ \\
\hline Preparação especifica para professores apresentadores & $\operatorname{sim}$ & não & não \\
\hline Reapresentação da aula & sim & não & sim \\
\hline Público beneficiado & distribuído & local & distribuído \\
\hline
\end{tabular}




\section{CONSIDERAÇÕES FINAIS}

Na intenção de enriquecer o modelo de ensino PMRT, e com a finalidade de motivar os alunos e professores, foi implantado um Ambiente Virtual de Aprendizagem - AVA no curso Superior de Tecnologia em Análise e Desenvolvimento de Sistemas - TADS como ferramenta auxiliar ao processo de ensino-aprendizagem, que proporcionou uma evolução no sistema e no perfil do aluno, tornando-o mais independente na busca dos artefatos de aula, do aprendizado concreto e da socialização, que é construída durante os períodos de formação do aluno. O aluno do TADS, em cada um dos municípios onde o curso está presente, passou a ser, o detentor de informações relevantes (notícias, informações da instituição de ensino, disponibilidade de ferramentas, entre outros) não só do seu próprio curso, mas também de outros cursos da UEA oferecidos nestes municípios na mesma modalidade. A maioria dos alunos e professores buscou na interatividade extraclasse, o recurso necessário para ultrapassar dificuldades de entendimento entre pessoas, da compreensão das disciplinas e da distância entre os municípios e seus representantes.

No mesmo cenário (curso TADS), foi realizado um experimento com uma das turmas, visando à melhoria do processo de aprendizagem. $O$ experimento teve como foco a maneira de assistir as aulas, mudando da forma coletiva para uma forma mais personalizada, pois o fato de trocar uma televisão disposta de maneira centralizada na sala de aula por computadores individuais resultou na mudança de comportamento, favorecendo a iniciativa do aluno, tornando a interatividade uma ferramenta importante, não somente pelo fato de professores e alunos poderem trocar idéias ao vivo, mas pelo retorno obtido por parte dos professores que apresentam as aulas em um estúdio de televisão não tendo contato visual com as turmas. Além da interatividade, o experimento também favoreceu a independência de cada aluno no momento de assistir as aulas. Explorando os recursos de mídia, puderam de forma personalizada dar ênfase a momentos diferentes durante a mesma aula, além de proporcionar uma 
maior comodidade, podendo assistir as aulas em outros lugares não dependendo dos recursos da sala de aula.

O experimento também chamou a atenção para dois outros fatores de extrema relevância: o primeiro diz respeito à necessidade das aulas serem apresentadas ao vivo (característica marcante do EP), o que hoje é um ponto positivo, pois permite a intervenção no momento em que o evento ocorre, por outro lado se os alunos podem ter acesso as aulas e levá-las em mídias particulares, torna o modelo flexível ao cumprimento de horário para as atividades inerentes as disciplinas (característica do EaD) e isso permite abordar o segundo fator relevante, pois questiona a forma como o professor assistente atua em relação a turma, acompanhando as atividades no mesmo horário da apresentação da aula, quando ele poderia prestar atendimento extra sala de aula em outro horário.

\subsection{Contribuições}

Teles e Duxbury (2000) descobriram que os professores contribuem com menos mensagens que os estudantes. No caso da sala de aula presencial, os professores dominavam de sessenta a oitenta por cento das aulas, muitas vezes com palestras expositivas. Já no caso das disciplinas on-line essa porcentagem do professor foi somente de dez a vinte por cento do total das mensagens postadas on-line. Ou seja, a participação on-line é inversa a participação presencial em termos de porcentagem estudantil e docente.

Dessa forma, a contribuição deste trabalho no que diz respeito à implantação de ferramentas tecnológicas se confirma nos resultados obtidos após um ano da implantação do Ambiente Virtual de Aprendizagem no curso de Tecnologia em Análise e Desenvolvimento de Sistemas que a partir da experiência justificou e incentivou o investimento em equipamentos e contratação de pessoal especializado para expandir a utilização do AVA para todos os cursos do EPMRT da Universidade do Estado do Amazonas, beneficiando 2.412 alunos distribuídos nos cursos de Tecnologia em Análise 
e Desenvolvimento de Sistemas, Educação Física e Licenciatura em Matemática em dezesseis municípios do Estado do amazonas.

Quanto às mudanças propostas na utilização e disposição de equipamentos e mídias em sala de aula, pode-se contribuir para o processo de aprendizagem proporcionando novas possibilidades de melhorias nas interatividades e flexibilidade na maneira de assistir as aulas.

\subsection{Trabalhos futuros}

O EPMRT é um modelo de educação que tem apresentado resultados expressivos no Estado do Amazonas. Diante de tamanha importância, este trabalho realizou estudos a cerca da infra-estrutura tecnológica relacionada a ferramentas computacionais e equipamentos multimídia utilizados em sala de aula, para contribuir para a melhoria do processo ensino-aprendizagem. Sugere-se como continuidade desse trabalho a investigação a respeito da infra-estrutura de transmissão de aula dando ênfase para qualidade de serviço - QoS e a criação de aplicações multimídia que sirvam de suporte ao modelo e que sejam adequadas as características da região Amazônica. 


\section{LISTA DE REFERÊNCIAS}

LANDIM, C. M. M. P. F. Educação a distância: algumas considerações. Rio de Janeiro: Claudia Maria das Mercês Paes Ferreira, 1997

JONASSEN, D. e GRABINGER, R.S. (1990) "Problems and Issues in designing hypertext/hypermedia for learning". IN: Desisng Hypermedia for learning. NATO ASI Series F: Computer and Systems Sciences, Vol. 67. New York: Springer-Verlag.

YOKAICHIYA, Daniela Kiyoko et al. Aprendizagem Colaborativa no Ensino a Distância - Análise da Distância Transacional. Acesso em: 06 ago 2009.

FILHO, Athail Rangel Pulino. Introdução ao Moodle. Ambiente de Aprendizagem. Módulo 1. Disponível em: Acesso em 06 ago. 2009.

KENSKI, Vânia Moreira. Tecnologias e Ensino Presencial e a Distância. 2 ed. Campinas: Papirus, 2003.

Koehler,A.; Taylor, K. Towards A Political Framework For Socio-Technical System Design.

Sage, A. P. Systems Engineering Education. IEEE transactions on systems, man, and cybernetics-part c: applications and reviews, vol. 30, no. 2, may 2000.

Barbosa, W. A.; Ramos, J. A. G. Proformar e a Educação no Amazonas. Manaus: UEA Edições / Editora Valer, 2008.

Warschauer, $M$ "Computer-mediated collaborative learning theory and practice". In. The Modem Language Journal, v. 81, n.4, 1997, p. 470-481.

Harasim, L. et. al. Redes de Aprendizagem. São Paulo: Senac, 2005

Telles, L. e Duxbury, N. The Networked Classrom - an assessment of the southern Interior Telecomunication Project. Facult of Education, Simon Fraser University. October, 1991. ERIC ED 348988.

Garland, I.; Wang, X.; Teles, L. Fostering creative through cross-disciplinary collaboration in an online dance course (ensaio apresentado na Computer supported collaborative Learning Conference). Palo Alto. Stanford University, dez. 1999.

Rebovich, G. J. The Evolution of Systems Engineering. SysCon 2008 - IEEE International Systems Conference, 2008. 
Gregoriades, A. Shin, J. e Sutcliffe, A. Human-Centred Requirements Engineering. Proceedings of the 12th IEEE International Requirements Engineering Conference, 2004.

Ottens, M. et al. Modeling engineering systems as socio-technical systems. 2004 IEEE International Conference on Systems, Man and Cybernetics, 2004.

Litto, F. M.; Formiga, M.(Org). Educação a distância: o estado da arte. São Paulo: Pearson Education do Brasil, 2009.

Wei, Z. Changing Teachers' Role to Facilitate Learner Autonomy of College English Majors in E-education. International Conference on Management of eCommerce and e-Government, 2009.

CASTELLS, M "A era da informação: economia sociedade e cultura". In: fim de Milênio, v. 3. São Paulo: Paz e Terra 2003.

VALENTE, J. A.; "Espiral da aprendizagem e as tecnologias da educação e comunicação: repensando conceitos". In: A tecnologia no ensino: implicações para a aprendizagem. São Paulo: Casa do Psicólogo, 2002, p. 15-37.

DEWEY, J. Experiência e educação, 3. ed. São Paulo: Nacional, 1979.

KHVILON, E. Aprendizaje abierto y a distancia: Considerações sobre tendências, políticas y estratégias. Paris: UNESCO. 2002.

ESTADO DO AMAZONAS. Lei n. 2.637, de 12 de janeiro de 2001. Cria a Universidade do Estado do Amazonas e dá outras providências. Diário Oficial do Estado do Amazonas, Manaus, AM, 2001.

BELLONI, Maria Luiza. Educação a distância. 3 ed. Campinas: Autores Associados, 2003. CSCW, Bibliography. Page on CSCW. Disponível em: $<$ http://www.telekooperation.de/cscw/>. Acesso em: 04 ago. 2009.

MORAN, José Manuel. O que é Educação a Distância. Disponível em: < http://www.eca.usp.br/prof/moran/dist.htm>. Acesso em 05 ago. 2009.

MORAN, José Manuel. Novos Caminhos no Ensino a Distância. Disponível em: < http://www.eca.usp.br/prof/moran/distanci.htm>. Acesso em 05 ago. 2009.

MEHLECKE, Querte Terezinha Conzi. Ambientes de Suporte Para Educação a Distância: A mediação para aprendizagem cooperativa. Disponível em: $<$ http://www.cinted.ufrgs.br/renote/fev2003/artigos/querte_ambientes.pdf> Acesso em 05 ago. 2009. 
LOHUIS, R.A.G. Computer Mediated Communication in Distance Education: Using the Internet? Disponível em: < http://wcd.student.utwente.nl/ ronny/literat.htm> acesso em 05 ago 2009.

ATAIDE, Maria Elza Miranda. Aspectos Legais que viabilizam a EAD no Brasil. Disponível em:

http://www.educor.desenvolvimento.gov.br/noticias/aspectos.htm> Acesso em 06 ago. 2009.

OTSUKA, Joice Lee. Fatores Determinantes na Efetividade de Ferramentas de Comunicação Mediada por Computador no Ensino à Distância. Disponível em: http://penta.ufrgs.br/pesquisa/joice/joice_ti.html\#sumula. Acesso em 06 ago. 2009.

Decreto n21.666, de 01 de fevereiro de 2001. Regulamenta a Lei n.2.637, de 12 de janeiro de 2001. Diário Oficial do Estado do Amazonas, Manaus, AM, 2001.

- Decreto n21.963, de 27 de junho de 2001. Autoriza o funcionamento do Curso Normal Superior da Universidade do Estado do Amazonas. Diário Oficial do Estado do Amazonas, Manaus, AM, 27 jun. 2001.

Conselho Estadual de Educação (CEE). Resolução n. 118, de 22 de dezembro de 2005. Reconhece o Curso Normal Superior da Universidade do Estado do Amazonas. Manaus: CEE, 2005. 